\author{
Military Technical College \\ Kobry El-Kobbah, \\ Cairo, Egypt.
}

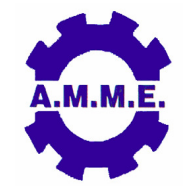

$15^{\text {th }}$ International Conference on Applied Mechanics and Mechanical Engineering.

\title{
A STUDY OF THE EFFECT OF CONVENTIONAL STRUCTURAL MATERIALS REPLACEMENT BY INNOVATIVE MATERIALS ON THE VEHICLE CRASHWORTHINESS (FRONTAL IMPACT)
}

\author{
H. M. Elgamal ${ }^{\star}$, M. M. Moussa* and M. M. Elnomrossy**
}

\begin{abstract}
Several approaches were investigated in order to achieve the goal of producing a lighter and safer vehicle. These approaches included studying of downsize the vehicle (applied especially after 1973); and the replacement of conventional structural materials with innovative materials, which gave similar or better performance with less weight. Almost every part of the vehicle structure was investigated by replacement with another one made from non-conventional material.

The main goal of this paper is to study the vehicle structural mechanics during crash (frontal impact) and to search for the most suitable type of composite materials to replace the conventional one in individual automotive structural parts to improve the performance of the vehicle by decreasing the vehicle weight, increasing the power to - weight ratio and improve the energy absorption capacity.
\end{abstract}

\section{KEY WORDS}

Vehicle structure, Vehicle Crashworthiness, Composite Materials.

* Egyptian Armed Forces.

** Assist. Professor, French University, Cairo, Egypt 


\section{INTRODUCTION}

Efficiency and dynamic behavior of a vehicle are strongly affected by its weight. Taking into consideration comfort, safety and emissions in modern automobiles, lightweight design is more of a challenge than ever in automotive engineering. Several approaches were investigated in order to achieve the goal of producing a lighter and safer vehicle. These approaches includes: to downsize the vehicle (applied especially after 1973); another approach is to substitute conventional structural materials with innovative materials, which give the same or better performance with less weight. Almost every part of the vehicle structures was investigated by replacement with another one made from non-conventional material. For example vehicle frame was replaced with another made totally from aluminum (made by Ford Corporation). Also the steel body was replaced by aluminum one (made in a model of Audi's cars). The new trend is to replace steel structural parts with aluminum reinforced ones, sometimes the reinforcement could be carbon fibers, but this is limited to racing and luxury cars only.

The role of new materials that fulfill these specified requirements is of great importance. The composite materials give the solution for these problems in design and can be tailored to satisfy the required needs. Because of their high strength, stiffness and low density, composites are currently being considered for many automotive applications due to the potential for the reduction of weight and more durable parts (improved in: corrosion resistance, fatigue life, wear and impact resistance), such as: drive shafts, springs, bumpers, interior panels, brake shoes and engine parts.

The main goal of this paper is to study the vehicle structural mechanics during crash (frontal impact) and to search for the most suitable type of composite materials (Kevlar/Epoxy and Carbon/Epoxy) to replace the conventional one in individual automotive structural parts (rails, bumper, fender, doors and wheelhouse) to improve the performance of the vehicle by decreasing the vehicle weight, increasing the power - to - weight ratio and improve the energy absorption capacity.

To make a good proposal for this study, the energy absorption of the different components of the model should be studied to make a good selection for the parts wish would be change its materials, and also the composite materials to be studied have to be specified.

\section{THEORETICAL STUDY}

Some theoretical concepts are in great position to obtain and manipulate different types of equations and to understand some related problems in crash analysis. The global model of the truck is described according to Finite Element Method as a numerical solution for the current problem.

The numerical study includes crash pulse, applications of the kinematics relationships in the analysis of restraint coupling and also the crash effects on the car structure and materials. 
The approach of energy absorption in composites for automotive crashworthiness is discussed.

\section{Crash Theoretical Study}

A basic characteristic of a vehicle structural response in crash testing and model simulation is the "crash signature," commonly referred to as the crash pulse. This is the deceleration time history at a point in the vehicle during impact. The crash pulse at a point on the rocker panel at the B-pillar is presumed to identify the significant structural behavior and the gross motion of the vehicle in a frontal impact. Other locations, such as the radiator and the engine, are frequently chosen to record the crash pulse for component dynamic analysis. The nature of the crash response depends on the mass, structural stiffness, damping at that location, and on external interactions from neighboring components. Applications of the kinematics relationships in the analysis of restraint coupling and ridedown efficiency are covered $[1,4]$.

\section{Energy Absorption in Composites for Automotive Crashworthiness}

Many criteria, in addition to a material being crashworthy, have to be met before one can begin the use of a particular composite as a crash energy absorber in automobiles. The primary ones are low costs involved in its manufacture and the materials being readily available. Once a composite material is identified to meet the above necessary requirements, one ought to know the effect that all the controllable parameters (like fiber arrangement, specimen geometry etc.) will have on its energy absorption capabilities, in an attempt to design the most crashworthy structure. Though in the past several researchers have investigated the energy absorption capabilities of composite materials, and now we can understand the effect of all the parameters on the energy absorption characteristics of each candidate composite material. [1], [5]

\section{LS_DYNA Approach of Modeling}

LS-DYNA uses an explicit Lagrangian finite element numerical method to solve three dimensional, dynamic, nonlinear, large displacement problems. The Lawrence Livermore National Laboratory first introduced the code in 1976. In the past 32 years, LS-DYNA has gained a solid ground in automotive analysis such as crashworthiness, occupant safety, and roadside hardware structures. LS-DYNA has numerous features that allow for the analysis of several nonlinear dynamic engineering problems. It has a large selection of finite element types, which include:

- One node lumped mass

- Two node spring and damper

- Two node truss and beam elements

- Three and four node shell elements

- Eight node solid and thick shell elements

It has a selection of over 100 material models ranging from the very simple elastic material to the elastic-plastic strain-rate-dependent material. The most advantageous capability of LS-DYNA over other finite element codes is its robust and reliable 
contact algorithms. Several types of contact interfaces can be defined in LS-DYNA. These include surface-to-surface, nodes to surface, nodes tied to surface, automatic single surface, and surface tied to surface contacts [2, 3].

\section{MODELING}

Finite element models of vehicles have been increasingly used in preliminary design analysis, component design, and vehicle crashworthiness evaluation, as well as roadside hardware design. Several vehicles models have been developed at U. S. Department of Transportation over the past years.

The finite element model of 1994 Chevrolet C-2500 pick-up truck which is used in this study, was developed at the NCAC for the Federal Highway Administration (FHWA) and the National Highway Traffic Safety Administration (NHTSA).

The Chevrolet C-2500 truck is a multi-purpose pickup truck. The vehicle obtained by the NCAC is a Regular- Cab, Fleet side Long-Box with a total length of 5.4 meters and a wheelbase of 3.34 meters. The engine is a 4.3 liter Vortec V6 with electronic fuel injection coupled to an automatic transmission with a rear wheel drive configuration.

The truck was first disassembled and grouped into seven main groups, the frame, front inner, front outer, cabin, doors, bed and miscellaneous. The three dimensional geometric data of each component was then obtained by using a passive digitizing arm connected to a desktop computer. The surface patches generated from specified digitized data were stored in AutoCAD in IGES format. These IGES files were then imported into PATRAN for mesh generation and model assembly. The model was then translated from PATRAN, which outputs a neutral file; into an LS-DYNA3D input file using a translator called HPD developed at the NCAC $[1,6,7]$.

Tables 1 and 2 list the main data and main parameters of the C2500- finite element model and some comparisons with the actual tested vehicle [9]. Figure 1 shows the isometric, top, and bottom views of the full C-2500 truck FE model, respectively, and Fig. 2 shows the C2500 pickup truck frame. The hood of the truck was removed in the top view for display purposes [9].

The studied model must be validated by subjecting this model to the crash tests, followed by comparison between the resulting curves (velocity and acceleration) at different locations of the vehicle (seat cross member, engine top and engine bottom), with that of the NCAC simulation and the actual test models. Figures $(3,4,5,6$ and 7) show that the results of the studied model are closely to the results of the NCAC model.

\section{MODEL RESULTS AND ANALYSIS}

It is important to analyze the energy absorption by the different components in the vehicle. This can be obtained in the simulation by computing the material internal 
energies in the model. The absorbed energy of the materials is the sum of the plastic strain energy and the elastic strain energy. Table 3 shows the percent of total energy mitigated through the different components $[1,8]$.

Based on the previous table, it is confirmed that the mentioned parts (rails, bumper, fender, doors and wheelhouse (Fig. 8)) are the effective parts which have $47.87 \%$ of the total internal energy absorption in the frontal impact with full rigid wall at an initial velocity of $55.8 \mathrm{~km} / \mathrm{hr}$.

Table 4 shows that the Kevlar epoxy and carbon epoxy have higher specific energy absorption [5].

Studied model was used to present the effect of front impact after changing the original material (steel) of some parts (rails, bumper, fender, doors and wheelhouse) with the proposed materials (Kevlar/epoxy, carbon/epoxy). The nodes 2061924 (driver seat) and 2061940 (engine top) as shown in Fig. 9 were chosen to be tested, because they represent the driver location and deformation during the crash test. $A$ comparison of displacement, velocity and internal energy is made for the chosen parts after changing their materials with composite materials. The effect of frontal impact is studied for each part individually, and the best composite material for each part is assigned.

Table 5 shows the characteristics of steel in the used LS-DYNA3D material model. The Mechanical properties of the unidirectional composite (Kevlar/Epoxy and Carbon/Epoxy) are shown in Table 6. The resulting curves are plotted in only the longitudinal direction ( $x$ direction), because the car did not rotate significantly around the z-axis even after the max. deformation point is reached, because of that, the $y$ and $z$ directions are neglected. The original material of the inner rails, total rails, bumper, doors, fender and wheel housing is changed to carbon/epoxy and Kevlar/epoxy.

The results for the displacement and velocity of nodes 2061924 and 2061940 and for the internal energy of the original material and when changing the parts materials to carbon/epoxy and to Kevlar/epoxy will be shown for each part individually. (Fig. 11 to Fig. 27 and Table7)

Figures 28 and 29 show that the kevlar/epoxy and carbon/epoxy provide the maximum displacement and maximum time when velocity reaches zero in case of changing bumper, fender, door and wheel housing material. The maximum internal energy is less than that of the original model (Fig.30) but accepted especially for the Kevlar/epoxy results. Figures 28 and 29 show also that the material changing of the main carrying load parts (rails) with carbon/epoxy provide the maximum displacement and maximum time at which velocity reach zero and so the maximum internal energy (Fig. 30).

The inner rails $(\mathrm{Ri})$ and the total rails $(\mathrm{Rt})$ material changed with carbon/epoxy, and in the same time the other parts (bomber (B), fender (F), door (D) and wheel housing (W)) materials changed with Kevlar/epoxy. 
Figures 34 and 35 show that changing of parts materials together generally provides the maximum displacement and maximum time at which velocity reach zero especially in the case of changing the inner rails, fender, door and wheel housing materials together. (See also Figures 31 and 32).

Figure 36 show that the internal energy of all the trials is less than that of the original model except in the case of changing the total rails, fender, door and wheel housing material together. (See also Fig. 33)

Tables 8 and 9 show that the maximum total weight reduction occurred in the last case (Rt-FDW), and this weight reduction gives a good effect on the C.G. location (C. G. move downward).

\section{CONCLUSIONS}

Because of their high strength, stiffness and low density, composites are currently being considered for many automotive applications due to the potential for the reduction of weight and more durable parts (improvement in: corrosion resistance, fatigue life, wear and impact resistance)

In this study composite materials are used instead of steel to reach a lighter safe vehicle.

The real crash tests are too much expensive and complicated. LS-DYNA is one of the advanced powerful finite element codes and is used in this study because of its high capabilities to simulate the crash tests, observe and measure a great amount of important parameters for crashworthiness evaluation.

A multi-purpose finite element model of a 1994 Chevrolet C-2500 pick-up truck is modified and used to address vehicle safety issues, including front impact with a full rigid wall by applying the composite material in the main rail (inner and total), bumper, fender, doors and wheel housing) separately and then in combinations.

Some parts were chosen (effective parts with maximum values of the internal energy) to test them by crashworthiness, then comparing the results (Displacement, Velocity and Internal energy) for each part by applying the composite material at the chosen part.

The usage of composite material in the selected parts individually or in combinations of parts together with respect to steel, showed that:

- carbon/epoxy is suitable for the main carrying load parts (rails)

- Kevlar/epoxy is suitable for the other parts (bumper, fender, door and wheel housing)

- Changing the total rails material with Carbon/EpoxyAS4/3501-6 and changing the other parts (fender, door and wheel housing) materials with Kevlar49/Epoxy gives $4.3 \%$ weight reduction, $214 \%$ increasing in the internal energy, $(1.1-19 \%)$ increasing in the maximum displacement and about 3\% decreasing in the time of zero velocity with respect to the original model results. 


\section{REFERENCES}

[1] Elgamal, H.M., "Implementation of Composite Materials in Ground Combat Vehicles", MSc. Thesis, MTC, Cairo, Egypt, 2009.

[2] Hallquist, J.O., "LS-DYNA3D Theoretical Manual", Livermore Software Technology Corporation, LSTC Report 1018, 1998.

[3] Hallquist, J.O., Stillman, D.W., Lin, T.L., "LS-DYNA3D Users Manual" Livermore Software Technology Corporation, LSTC Report 1007, Rev. 2, 1992.

[4] Matthew Huang, "Vehicle Crash Mechanics", USA, 2002.

[5] George C. Jacob, John F. Fellers, Srdan Simunovic and J. Michael Starbuck, "Energy Absorption in Polymer Composites for Automotive Crashworthiness", Journal of Composite Materials 2002; 36; 813.

[6] Begeman, P. D., and Prasad, P., "Human Ankle Impact Response in Dorsiflexion", SAE Technical Paper No. 902308. Reprinted in Hybrid III: The First Human-Like Crash Test Dummy, SAE PT-44, 1994.

[7] PAM CRASH User's manual vs12.1 Engineering System International, Paris, France, 1994.

[8] Eltaher, H.M., "Vehicle Structural Mechanics Considering Innovative Materials", MSc. Thesis, MTC, Cairo, Egypt, 2000.

[9] "FE Model of C2500 Pick-up Truck Report", FHWA/NHTSA, National Crash Anlysis Center, The George Washington University.

\section{LIST OF TABLES}

Table 1. C2500-finite element model.

\begin{tabular}{||l||c|}
\hline Number of Parts & 248 \\
\hline Number of Nodes & 66050 \\
\hline Number of Solids & 3561 \\
\hline Number of Beams & 153 \\
\hline Number of Springs & 22 \\
\hline Number of mass elements & 86 \\
\hline Number of Shells & 54028 \\
\hline Number of Elements & 57850 \\
\hline
\end{tabular}


Table 2. C2500 FEM - Actual tested vehicle comparison.

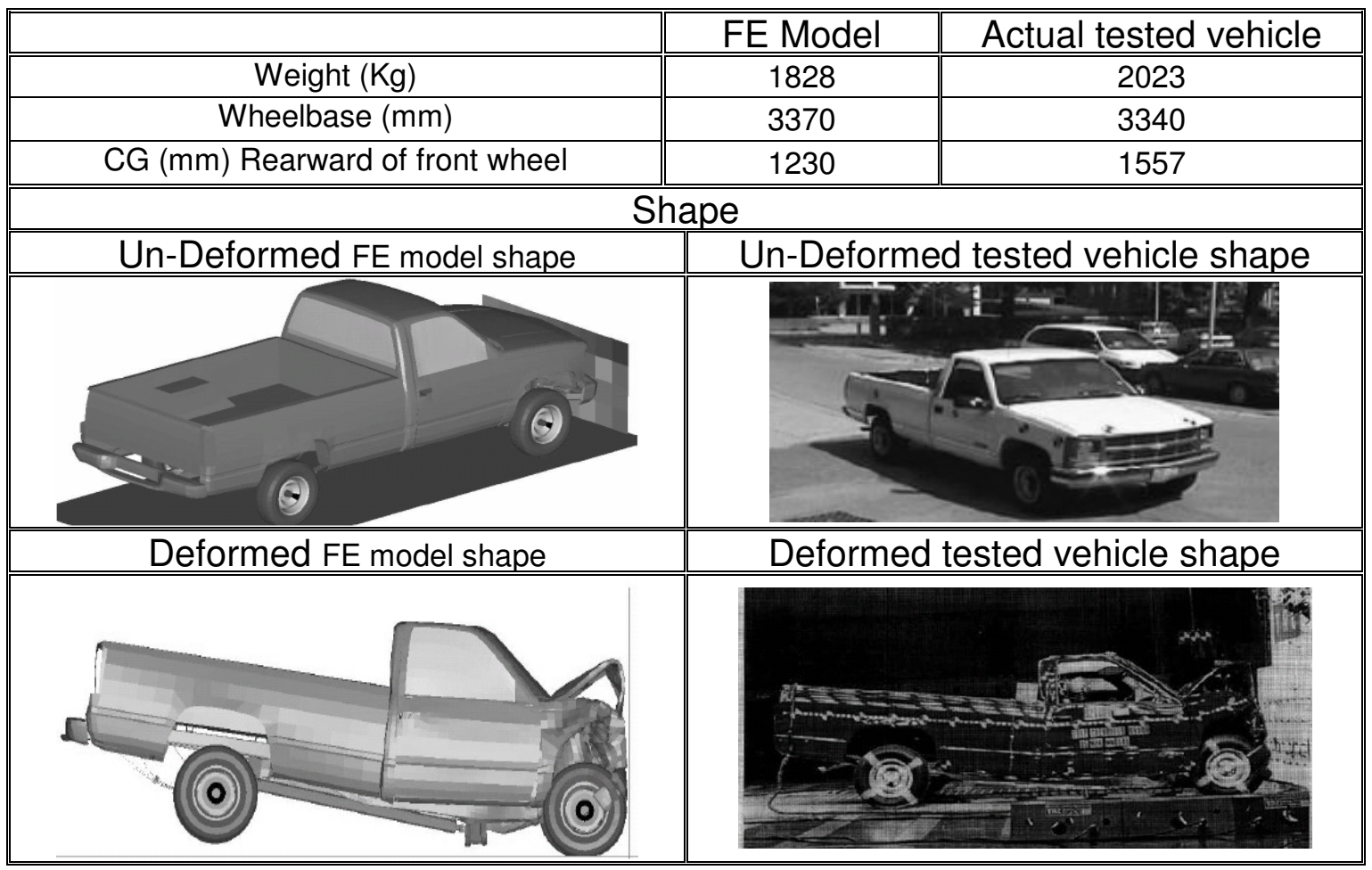

Table 3. Material internal energy for a $55.8 \mathrm{~km} / \mathrm{hr}$ frontal impact into a rigid wall.

\begin{tabular}{|c|c|c|c|c|}
\hline Material Parts & Internal Energy (kJ) & \multicolumn{3}{|c|}{ Percentage } \\
\hline Whole Vehicle & 203.17 & \multicolumn{3}{|c|}{$100 \%$} \\
\hline Total front rails & 64.756 & $31.87 \%$ & \multirow{5}{*}{$\begin{array}{l}\bar{\pi} \\
\text { Oٓ }\end{array}$} & \multirow{5}{*}{$\begin{array}{l}\overbrace{}^{\circ} \\
\stackrel{\infty}{\infty} \\
\stackrel{\gamma}{\gamma}\end{array}$} \\
\hline Bumper & 16.647 & $8.19 \%$ & & \\
\hline Fender & 11.173 & $5.5 \%$ & & \\
\hline Wheelhouse & 4.4468 & $2.19 \%$ & & \\
\hline Doors & 0.23642 & $0.12 \%$ & & \\
\hline
\end{tabular}

Table 4. Range of values for the specific energy absorption $E_{s}[6]$.

\begin{tabular}{|c|c|c|c|c|c|c|c|c|c|}
\hline Parameter & (1) & (2) & (3) & (4) & (5) & (6) & (7) & (8) & (9) \\
\hline Fiber type & Kevlar & Carbon & Kevlar & Kevlar & Kevlar & Kevlar & Kevlar & Kevlar & Kevlar \\
\hline $\mathrm{E}_{\mathrm{S}}(\mathrm{kJ} / \mathrm{kg})$ & 80 & 90 & 70 & 75 & 76 & 67 & 78 & 65 & 78 \\
\hline
\end{tabular}

Note: All tests were carried out with Epoxy matrix, $\pm\left[45^{\circ}\right]$ fiber arch., $15.75 \%$ volume fraction, slow cooled proc. cond., $10 \mathrm{~m} / \mathrm{s}$ test speed, chamfer trigger and $\mathrm{D} / \mathrm{t}=25 \mathrm{spec}$. $\mathrm{dim}$.

Table 5. The characteristics of steel material model properties.

\begin{tabular}{|c|c|}
\hline \multicolumn{2}{|c|}{ MAT ELASTIC } \\
\hline \hline Density & $7.89,8.06 \mathrm{E}-09 \mathrm{t} / \mathrm{mm}^{3}$ \\
\hline Young's modulus & $200,000 \mathrm{~N} / \mathrm{mm}^{2}$ \\
\hline Poisson's ratio & 0.3 \\
\hline
\end{tabular}


Table 6. Typical properties of unidirectional composites.

\begin{tabular}{|l|c||c||}
\hline \multicolumn{1}{|c|}{ Property } & Kevlar49/Epoxy & Carbon/EpoxyAS4/3501-6 \\
\hline \hline Density $[\mathrm{g} / \mathrm{cc}]$ & 1.380 & 1.58 \\
\hline Longitudinal Modulus $\mathrm{E}_{1}[\mathrm{GPa}]$ & 75.8 & 142 \\
\hline Transverse Modulus $\mathrm{E}_{2}[\mathrm{GPa}]$ & 5.5 & 10.3 \\
\hline Inplane Shear Modulus $\mathrm{G}_{12}[\mathrm{GPa}]$ & 2.07 & 7.2 \\
\hline Poisson's Ratio $v_{12}$ & 0.34 & 0.27 \\
\hline Longitudinal Tensile Strength $\mathrm{F}_{1 \mathrm{t}}[\mathrm{MPa}]$ & 1380.0 & 1830.0 \\
\hline Transverse Tensile Strength $\mathrm{F}_{2 \mathrm{t}}[\mathrm{MPa}]$ & 34.5 & 57 \\
\hline Inplane Shear Strength $\mathrm{F}_{6}[\mathrm{MPa}]$ & 44.1 & 71 \\
\hline Longitudinal Compressive Strength $\mathrm{F}_{1 \mathrm{c}}$ & 586.0 & 1096 \\
\hline Transverse Compressive Strength $\mathrm{F}_{2 \mathrm{c}}$ & 138.0 & 228 \\
\hline Interlaminar Shear Strength $\left(\mathrm{F}_{4} \mathrm{orF}_{5}\right)$ & 48.69 & 48.69 \\
\hline Fiber Volume Fraction $\mathrm{V}_{\mathrm{f}}[\%]$ & 60 & 60 \\
\hline
\end{tabular}

Table 7. Results Analysis.

\begin{tabular}{|c|c|c|c|c|c|c|}
\hline \multirow{2}{*}{\multicolumn{2}{|c|}{ Model }} & \multicolumn{2}{|c|}{ Node 2061924 (Driver Seat) } & \multicolumn{2}{|c|}{ Node 2061940 (engine top) } & \multirow{2}{*}{$\begin{array}{l}\text { Internal Energy } \\
(k \mathrm{~J})\end{array}$} \\
\hline & & $\begin{array}{c}\text { Maximum } \\
\text { Displacement }(\mathrm{mm})\end{array}$ & $\begin{array}{c}\text { Time (Zero } \\
\text { Velocity) }\end{array}$ & $\begin{array}{c}\text { Maximum } \\
\text { Displacement }\end{array}$ & $\begin{array}{l}\text { Time (Zero } \\
\text { Velocity) }\end{array}$ & \\
\hline Origina & Model & 770.74 & 0.0866 & 664.5 & 0.05 & 205.24 \\
\hline \multicolumn{7}{|c|}{ Changing of parts materials individually } \\
\hline \multicolumn{2}{|c|}{ Rail inner $(\mathrm{C})$} & 930.14 & 0.1162 & 676.93 & 0.0491 & 50.894 \\
\hline \multicolumn{2}{|c|}{ Rail Total (C) } & 915.92 & 0.0993 & 676.11 & 0.048 & 599.38 \\
\hline \multicolumn{2}{|c|}{ Bomber (K) } & 794.54 & 0.0867 & 670.88 & 0.0485 & $248 \mathrm{E} 11$ \\
\hline \multirow{2}{*}{$\begin{array}{l}\text { Fender } \\
(\mathrm{F})\end{array}$} & Carbon & 834.6 & 0.1068 & 663.68 & 0.0496 & 184.62 \\
\hline & Kevlar & 820.84 & 0.1013 & 664.82 & 0.0501 & 198.5 \\
\hline \multirow{2}{*}{ Doors (D) } & Carbon & 777.32 & 0.101 & 662.25 & 0.0494 & 170.32 \\
\hline & Kevlar & 777.14 & 0.0887 & 662.92 & 0.0494 & 194.21 \\
\hline \multirow{2}{*}{$\begin{array}{l}\text { Wheel } \\
\text { Housing }\end{array}$} & Carbon & 806.19 & 0.1052 & 666.77 & 0.0497 & 204.24 \\
\hline & Kevlar & 807.07 & 0.1052 & 666.77 & 0.0492 & 203.38 \\
\hline \multicolumn{7}{|c|}{ Changing of parts materials together } \\
\hline \multicolumn{2}{|c|}{ B-F } & 843.28 & 0.1107 & 671.92 & 0.0499 & 510.8E8 \\
\hline \multicolumn{2}{|c|}{ F-D-W } & 802.96 & 0.0915 & 665.43 & 0.0493 & 177.06 \\
\hline \multicolumn{2}{|c|}{$\mathrm{Ri}-\mathrm{F}$} & 978.5 & 0.0895 & 671.55 & 0.0464 & 31.557 \\
\hline \multicolumn{2}{|c|}{$\mathrm{Ri}-\mathrm{FDW}$} & 972.36 & 0.151 & 677.15 & 0.0489 & 34.52 \\
\hline \multicolumn{2}{|c|}{ Rt - FDW } & 921.09 & 0.0845 & 671.58 & 0.0488 & 645.13 \\
\hline
\end{tabular}


Table 8. Weight reduction and change in C.G. location for material changing of each part individually.

\begin{tabular}{|c|c|c|c|c|c|c|c|c|c|c|}
\hline \multirow{3}{*}{\multicolumn{2}{|c|}{$\begin{array}{c}\text { Models } \\
\text { Original }\end{array}$}} & \multirow{4}{*}{$\begin{array}{c}\begin{array}{c}\text { Weight } \\
\text { (Ton) }\end{array} \\
1.63447 \\
1.62097\end{array}$} & \multicolumn{3}{|c|}{ Center of gravity } & \multirow{4}{*}{ 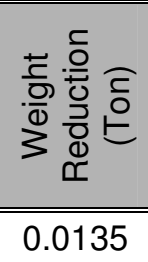 } & \multirow{2}{*}{\multicolumn{3}{|c|}{ Change in C. G. }} & \multirow{4}{*}{ 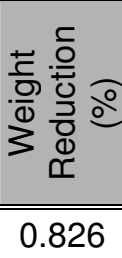 } \\
\hline & & & \multirow{3}{*}{$\begin{array}{c}\begin{array}{l}\mathrm{X}^{*} \mathrm{E} 3 \\
(\mathrm{~mm})\end{array} \\
2.4406 \\
2.4311\end{array}$} & \multirow{3}{*}{$\begin{array}{c}\begin{array}{c}Y^{*} \mathrm{E} 1 \\
(\mathrm{~mm})\end{array} \\
-2.0746 \\
-2.1014\end{array}$} & \multirow{3}{*}{$\begin{array}{l}\begin{array}{l}Z^{*} \mathrm{E} 2 \\
(\mathrm{~mm})\end{array} \\
6.5172 \\
6.5333\end{array}$} & & & & & \\
\hline & & & & & & & $\Delta \mathrm{X}$ & $\Delta \mathrm{Y}$ & $\Delta \mathrm{Z}$ & \\
\hline & Carbon & & & & & & -0.0094 & -0.0268 & 0.0161 & \\
\hline inner & Kevlar & 1.62055 & 2.4308 & -2.1022 & 6.5338 & 0.01392 & -0.0098 & -0.0272 & 0.0166 & 0.852 \\
\hline Hail & Carbon & 1.6086 & 2.4217 & -2.1274 & 6.5480 & 0.02587 & -0.0188 & -0.0528 & 0.0308 & 1.583 \\
\hline & Kevlar & 1.60778 & 2.4211 & -2.1291 & 6.5490 & 0.02669 & -0.0194 & -0.0545 & 0.0318 & 1.633 \\
\hline & Carbon & 1.62349 & 2.4273 & -2.0883 & 6.5267 & 0.01098 & -0.0133 & -0.0137 & 0.0095 & 0.672 \\
\hline (I) & Kevlar & 1.62315 & 2.4269 & -2.0888 & 6.5270 & 0.01132 & -0.0137 & -0.0142 & 0.0098 & 0.692 \\
\hline Fender & Carbon & 1.62289 & 2.4323 & -2.0904 & 6.5001 & 0.01158 & -0.0083 & -0.0157 & -0.0170 & 0.708 \\
\hline 1 ctiues & Kevlar & 1. & 2.4320 & -2 . & 996 & 0.0 & 85 & -0.0162 & -0.0176 & 0.731 \\
\hline & Carbon & 1.6169 & 2.4255 & -2.0979 & 6.4662 & 0.01757 & -0.0150 & -0.0232 & -0.0509 & 1.075 \\
\hline & Kevlar & 1.61634 & 2.4251 & -2.0986 & 6.4646 & 0.01813 & -0.0155 & -0.0240 & -0.0526 & 1.109 \\
\hline Door & Carbon & 1.6099 & 2.4400 & -2.1049 & 6.4753 & 0.02457 & -0.0005 & -0.0303 & -0.0419 & 1.503 \\
\hline & Kevlar & 1.60912 & 2.4400 & -2.105 & 6.4740 & 0.02535 & -0.0005 & -0.0312 & -0.0432 & 1.551 \\
\hline & Carbon & 1.62794 & 2.4358 & -2.0783 & 6.5145 & 0.00653 & -0.0047 & -0.0037 & -0.0026 & 0.399 \\
\hline & Kevlar & 1.62774 & 2.4357 & -2.0784 & 6.5144 & 0.00673 & -0.0049 & -0.0038 & -0.0027 & 0.412 \\
\hline
\end{tabular}

Table 9. Weight reduction and change in C.G. location for combinations of parts materials change.

\begin{tabular}{|c|c|c|c|c|c|c|c|c|c|c|}
\hline \multirow{2}{*}{\multicolumn{2}{|c|}{ Models }} & \multirow{3}{*}{$\begin{array}{c}\begin{array}{c}\text { Weight } \\
\text { (Ton) }\end{array} \\
1.63447\end{array}$} & \multicolumn{3}{|c|}{ Center of gravity } & \multirow{3}{*}{ 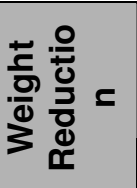 } & \multirow{2}{*}{\multicolumn{3}{|c|}{ Change in C. G. }} & \multirow{3}{*}{ 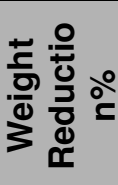 } \\
\hline & & & \multirow{2}{*}{\begin{tabular}{|c|}
$\begin{array}{c}X^{\star} \mathrm{E} 3 \\
(\mathrm{~mm})\end{array}$ \\
2.44065
\end{tabular}} & \multirow{2}{*}{$\begin{array}{c}Y^{*} E 1 \\
(\mathrm{~mm}) \\
-2.07462\end{array}$} & \multirow{2}{*}{$\begin{array}{c}\begin{array}{c}Z^{*} E 2 \\
(\mathrm{~mm})\end{array} \\
6.51723\end{array}$} & & & & & \\
\hline \multicolumn{2}{|c|}{ Original } & & & & & & $\Delta \mathbf{X}$ & $\Delta \mathbf{Y}$ & $\Delta \mathbf{Z}$ & \\
\hline \multirow{5}{*}{ 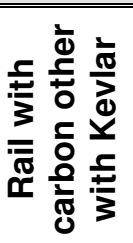 } & F-B & 1.6112 & 2.4182 & -2.10533 & 6.50939 & 0.02327 & -0.02245 & -0.03071 & -0.00784 & 1.424 \\
\hline & F-D-W & 1.59043 & 2.42628 & -2.12681 & 6.45277 & 0.04404 & -0.01437 & -0.05219 & -0.06446 & 2.694 \\
\hline & Ri-F & 1.60903 & 2.42245 & -2.11806 & 6.51571 & 0.02544 & -0.0182 & -0.04344 & -0.00152 & 1.556 \\
\hline & Ri-FDW & 1.57694 & 2.41640 & -2.15482 & 6.46876 & 0.05753 & -0.02425 & -0.0802 & -0.04847 & 3.52 \\
\hline & Rt-FDW & 1.56456 & 2.40664 & -2.18199 & 6.48342 & 0.06991 & -0.03401 & -0.10737 & -0.03381 & 4.277 \\
\hline
\end{tabular}

Note:

Positive $\Delta \mathrm{X}(+\mathrm{F})$.. C.G. move forward Positive $\Delta Y(+R)$. C.G. move right Positive $\Delta Z(+D)$.. C.G. move downward
Negative $\Delta \mathrm{X}(-\mathrm{B})$.. C.G. move backward Negative $\Delta Y(-L)$.. C.G. move lift Negative $\Delta Z(-U)$.. C.G. move upward 


\section{LIST OF FIGURES}
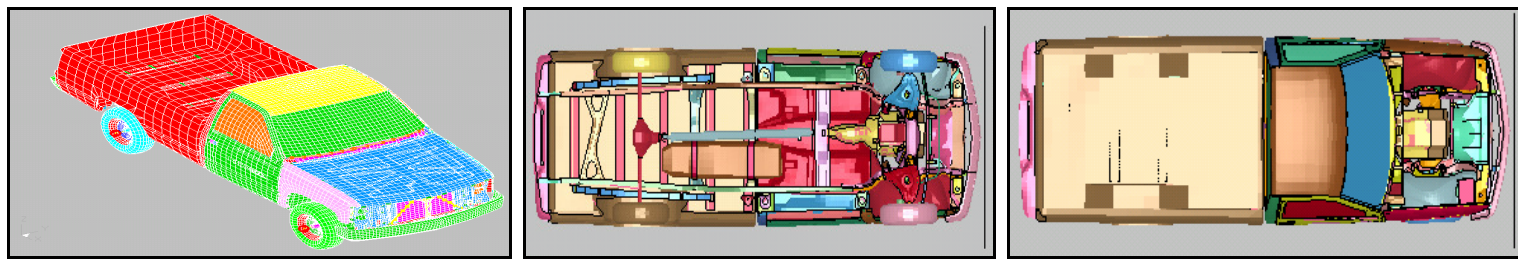

Fig.1. Isometric, bottom and top (no hood) views of the truck model.

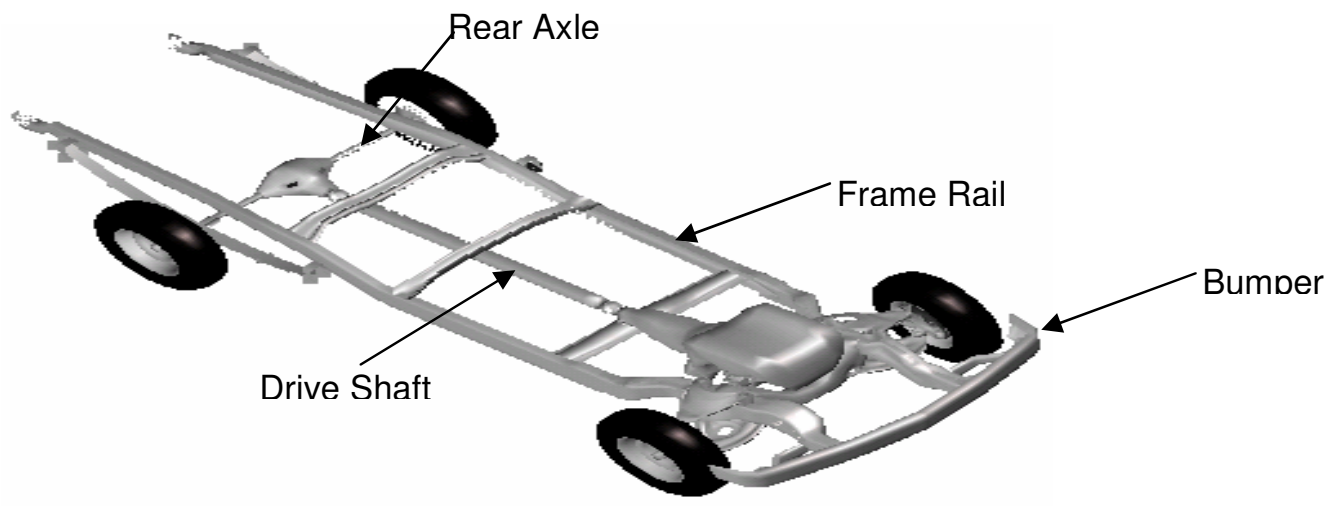

Fig. 2. C2500 pickup truck frame.

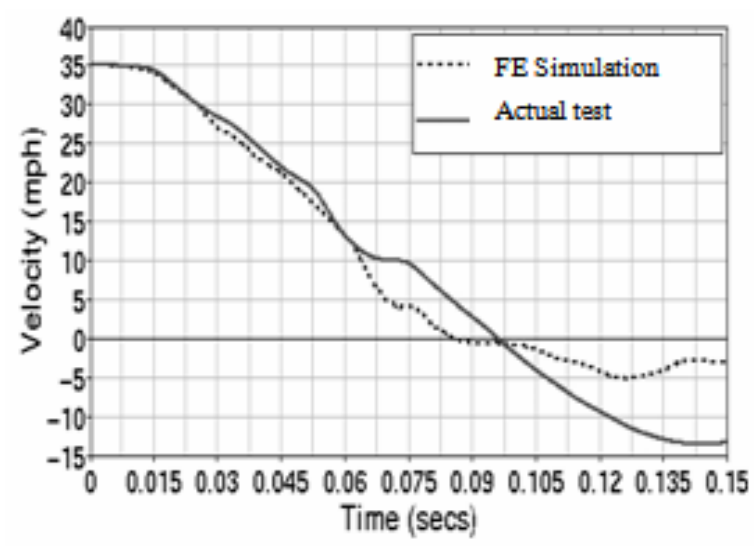

(a) NCAC FE model and actual test [9]

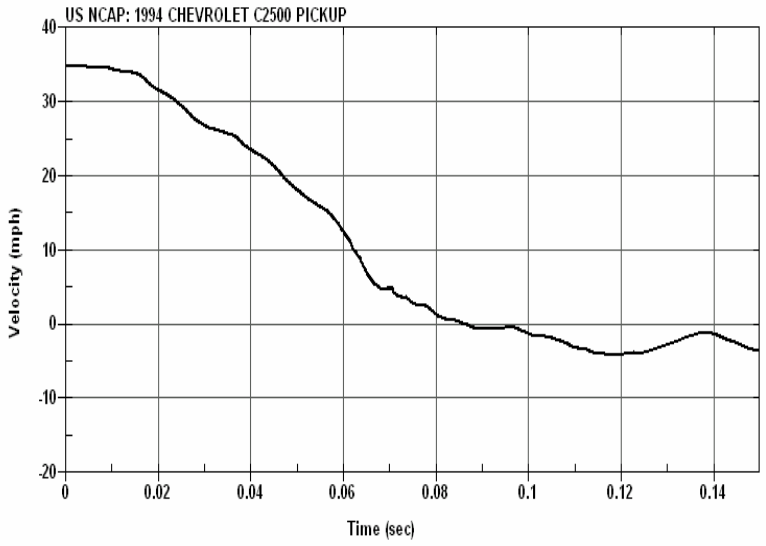

(b) Studied model.

Fig. 3. Seat cross member, average velocity comparison. 


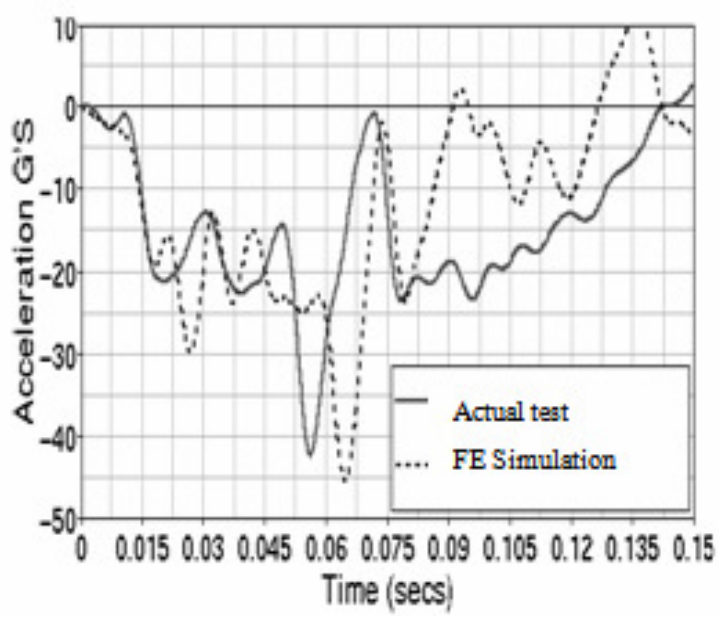

(a) NCAC FE model and actual test

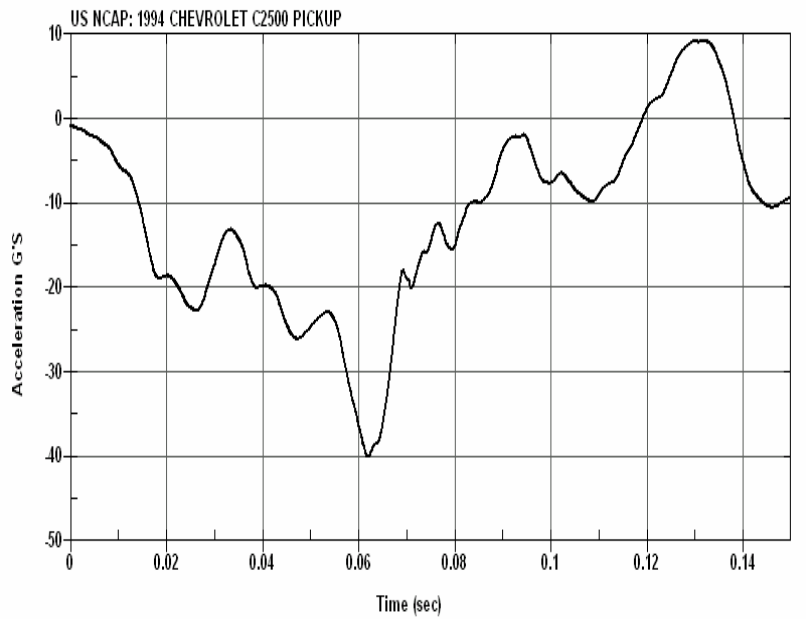

(b) Studied model.

Fig. 4. Seat cross member, average acceleration comparison.

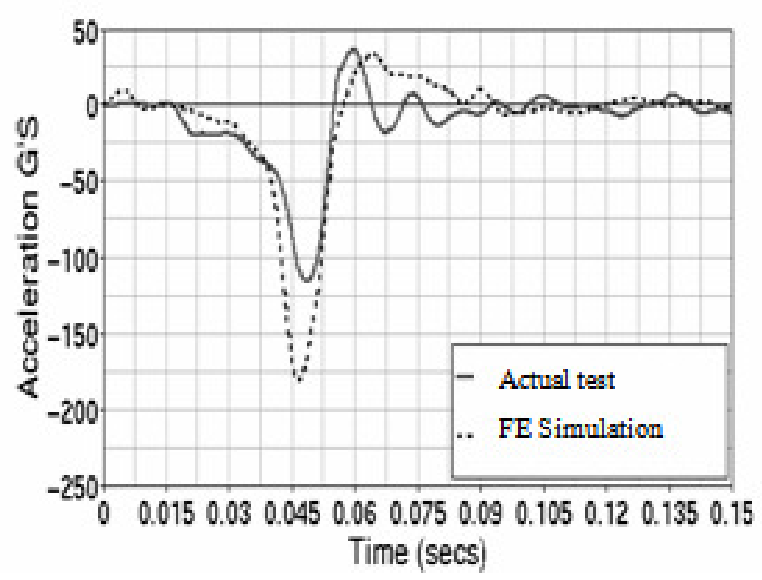

(a) NCAC FE model and actual test

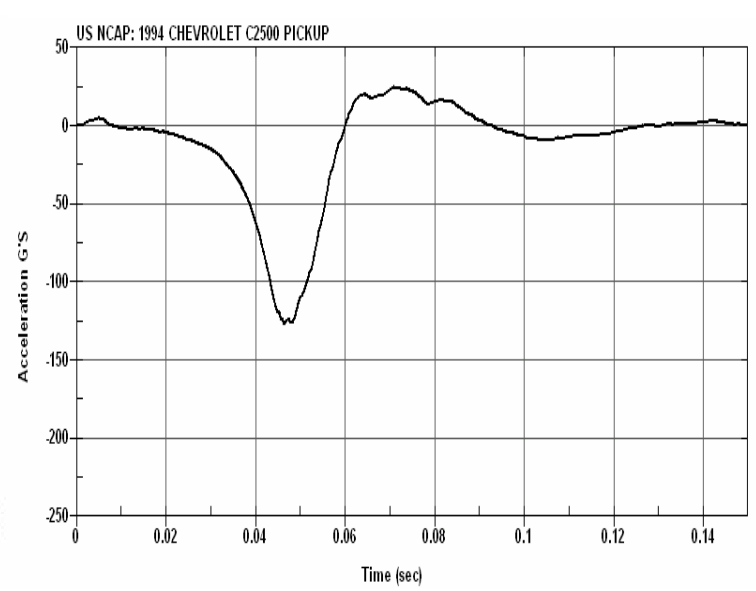

(b) Studied model.

Fig.5. Engine top, average acceleration comparison.

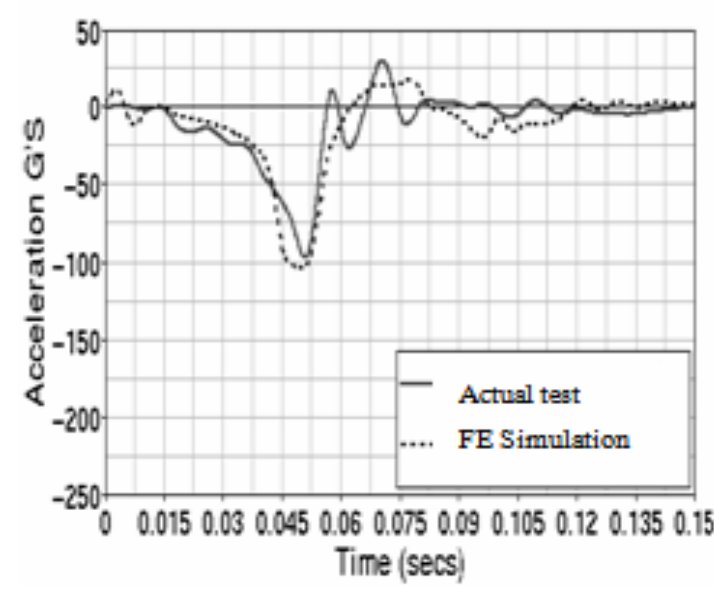

(a) NCAC FE model and actual test

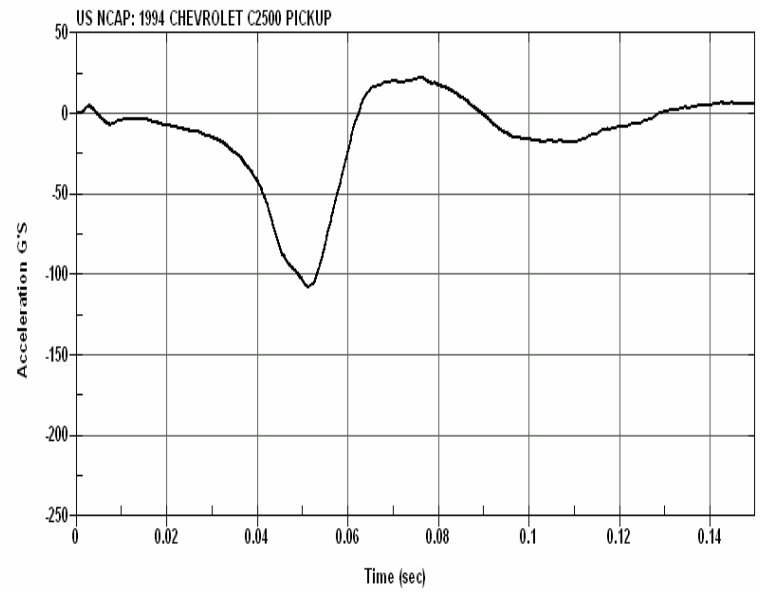

(b) Studied model

Fig. 6. Engine bottom, average acceleration comparison. 


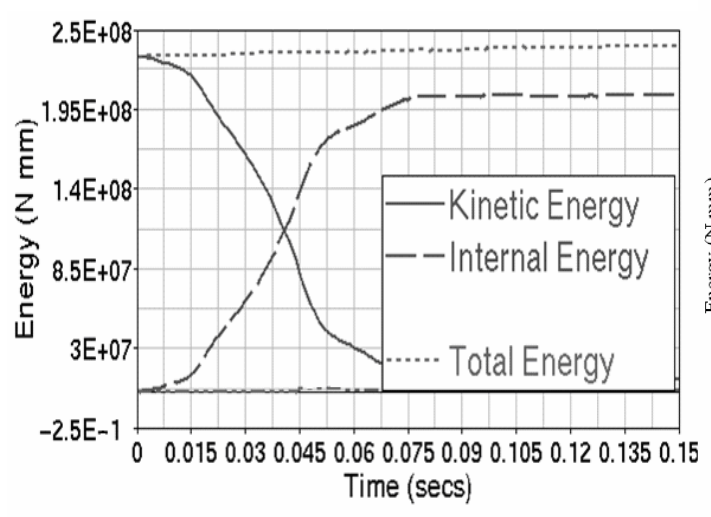

(a) NCAC FE model

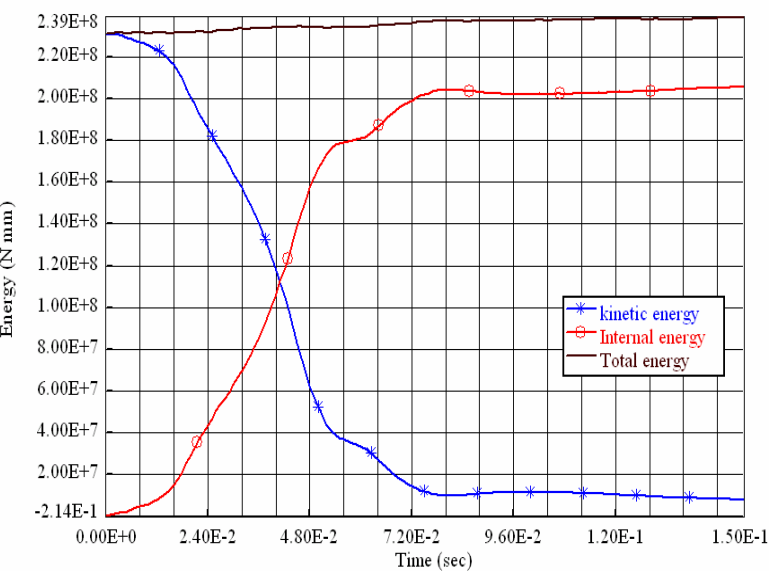

(b) Studied model

Fig. 7. Energy balance comparison.

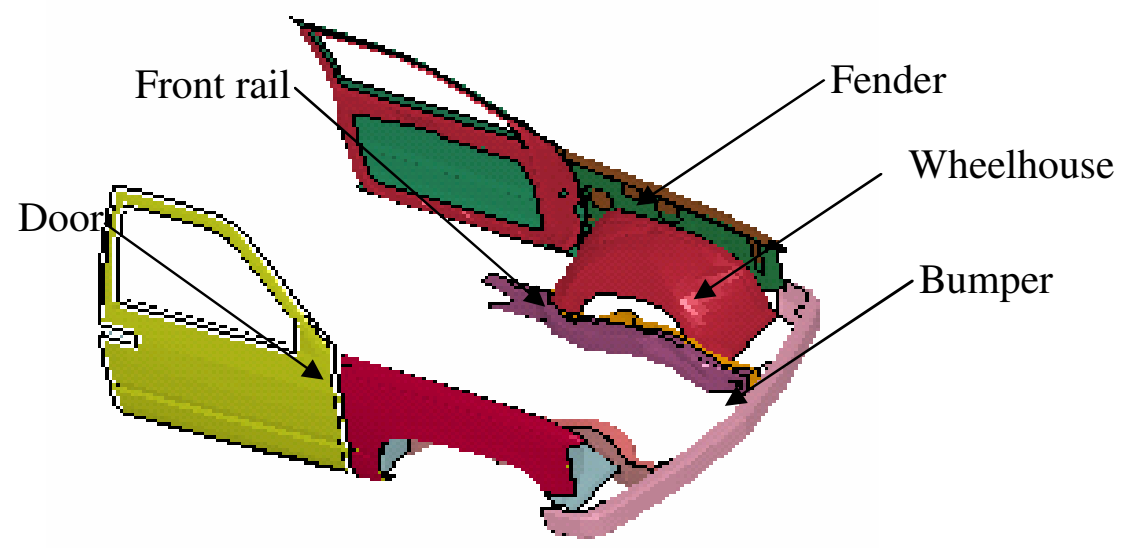

Fig. 8. Front rails, bumper, fender, wheelhouse, and doors.
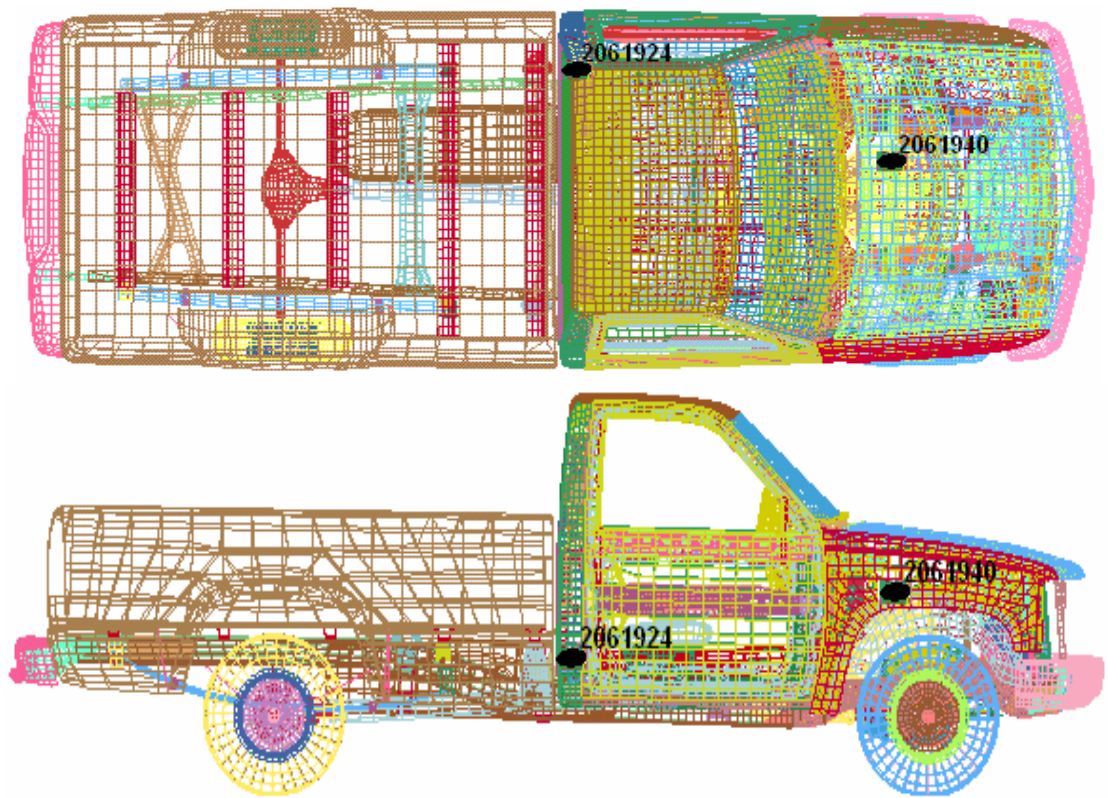

Fig. 9. Position of tested nodes 2061924 and 2061940. 


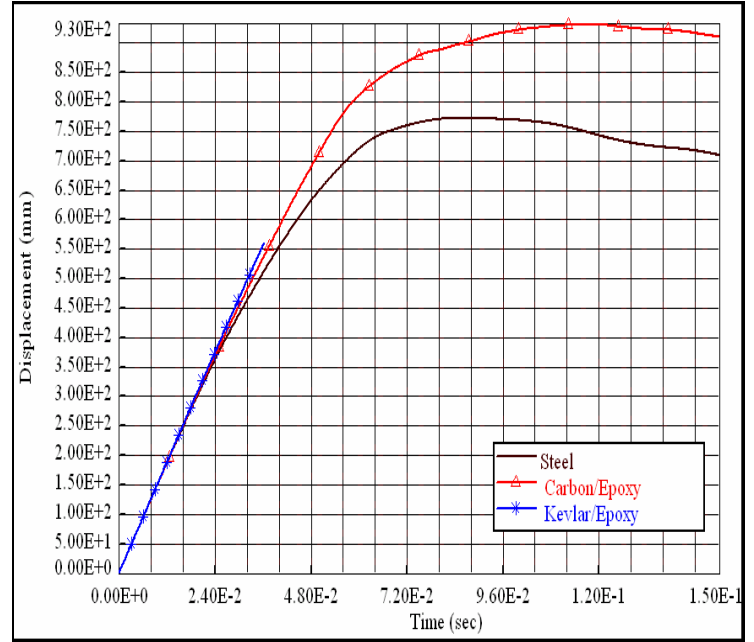

(a) Displacement

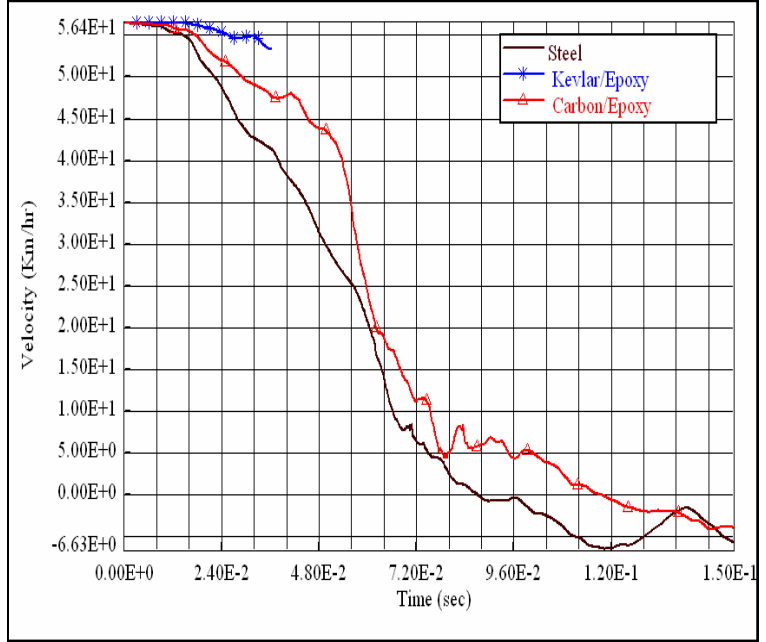

(b) Velocity

Fig. 10. Displacement and velocity of node 2061924 due to inner rail material change.

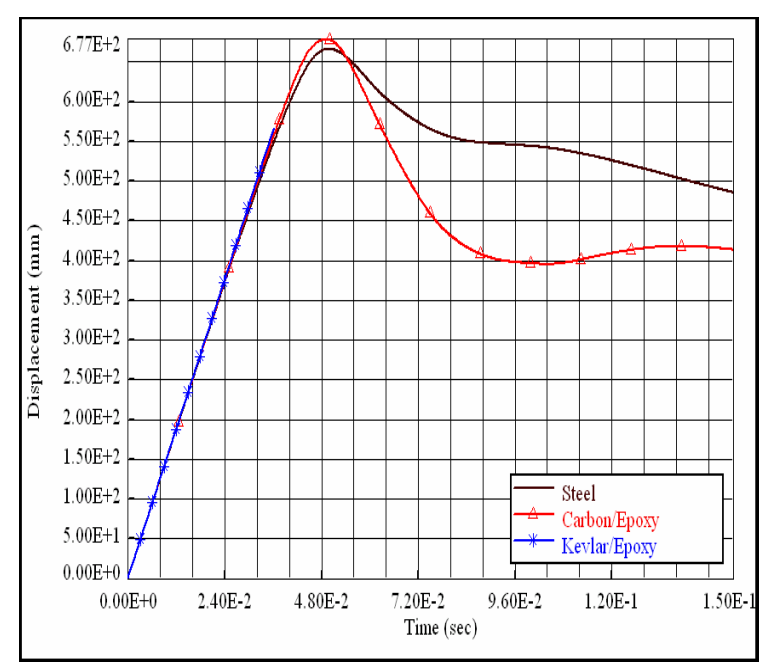

(a) Displacement

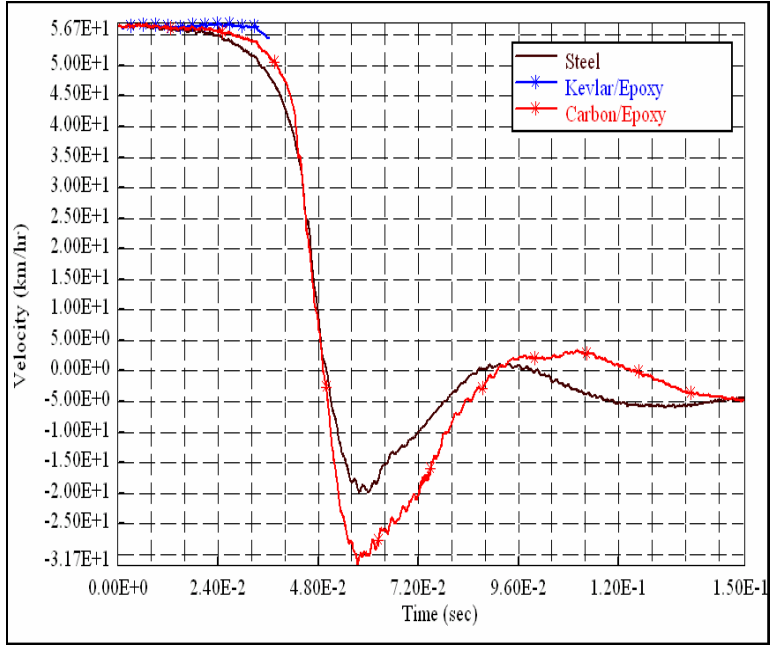

(b) Velocity

Fig. 11. Displacement and velocity of node 2061940 due to inner rails material change.

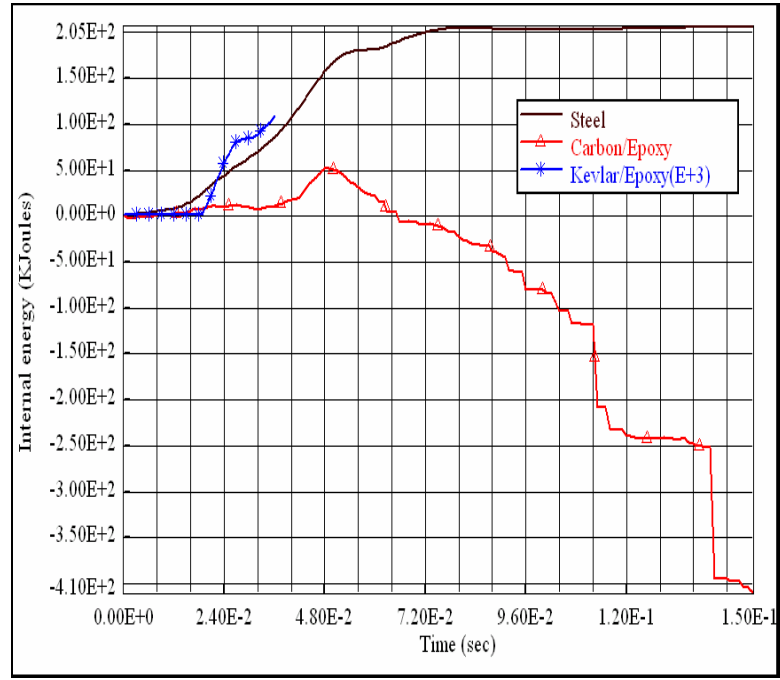

Fig. 12. Internal Energy due to inner rails material change. 


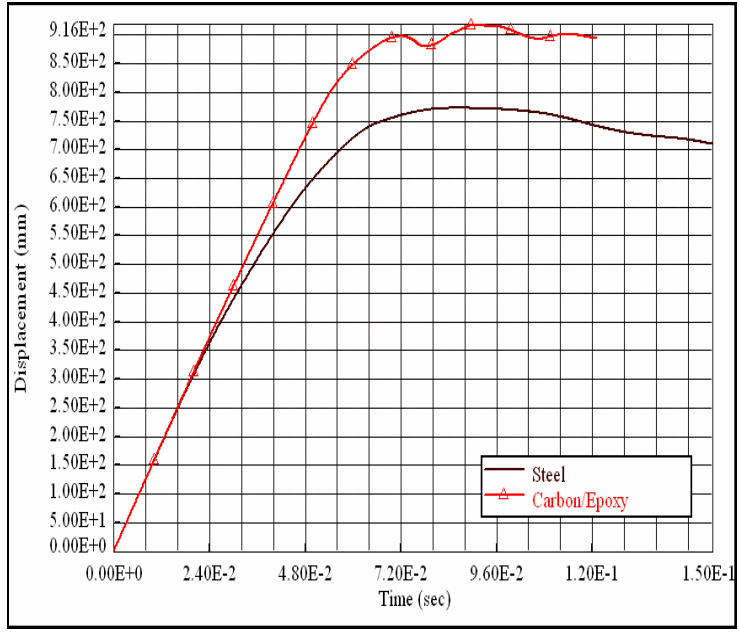

(a) Displacement

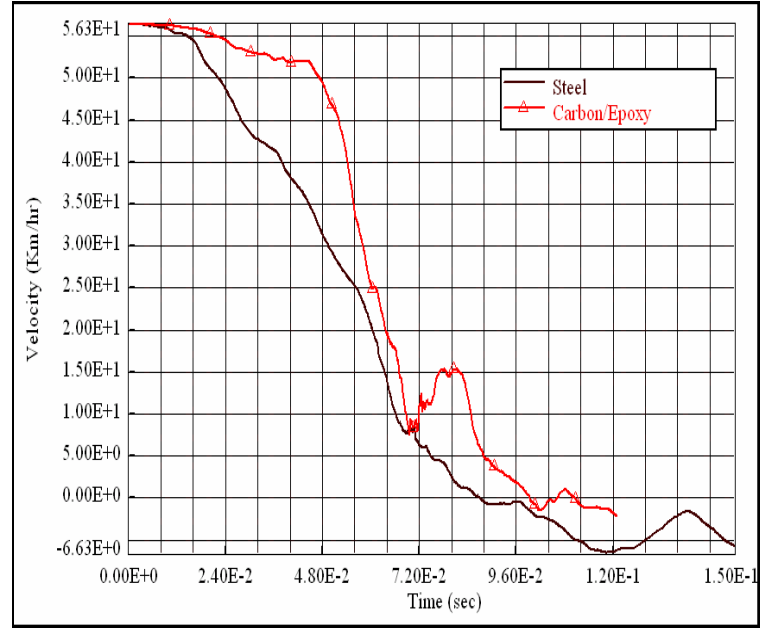

(b) Velocity

Fig. 13. Displacement and velocity of node 2061924 due to total rails material change.

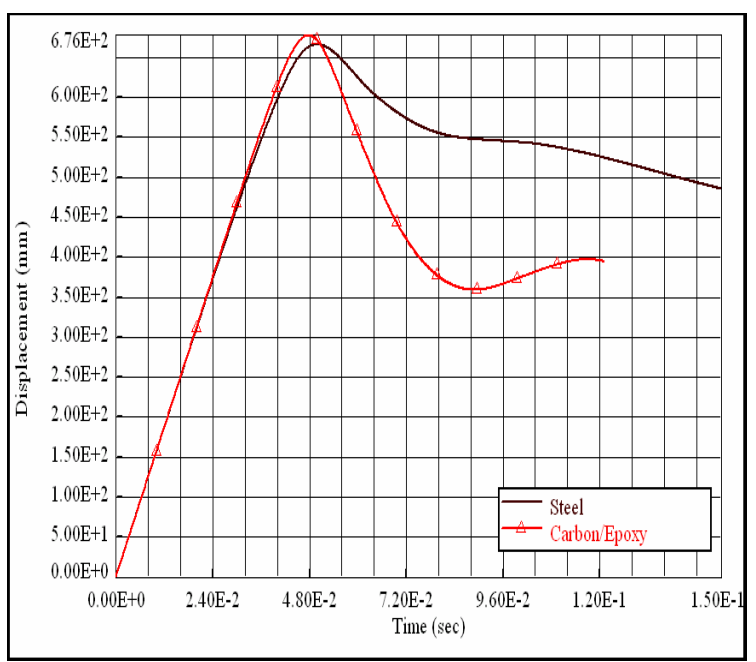

(a) Displacement

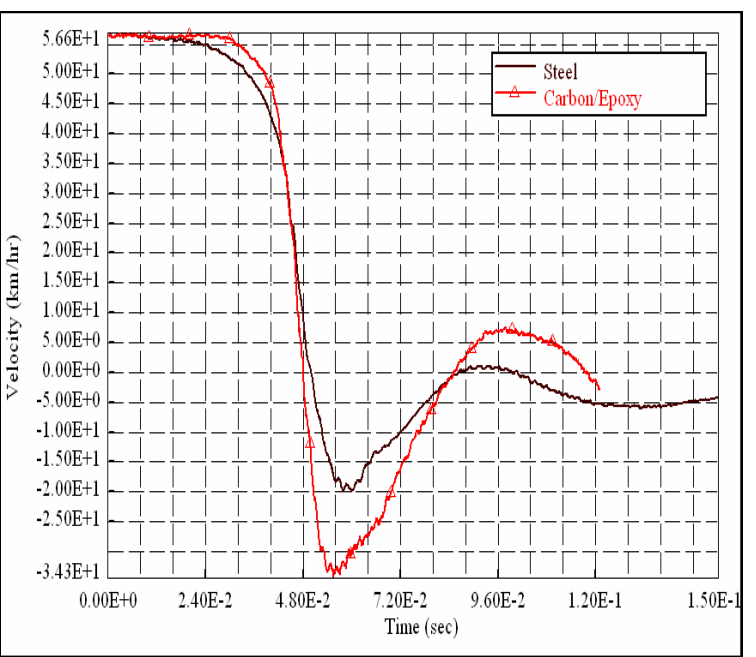

(b) Velocity

Fig. 14 Displacement and velocity of node 2061940 due to total rails material change.

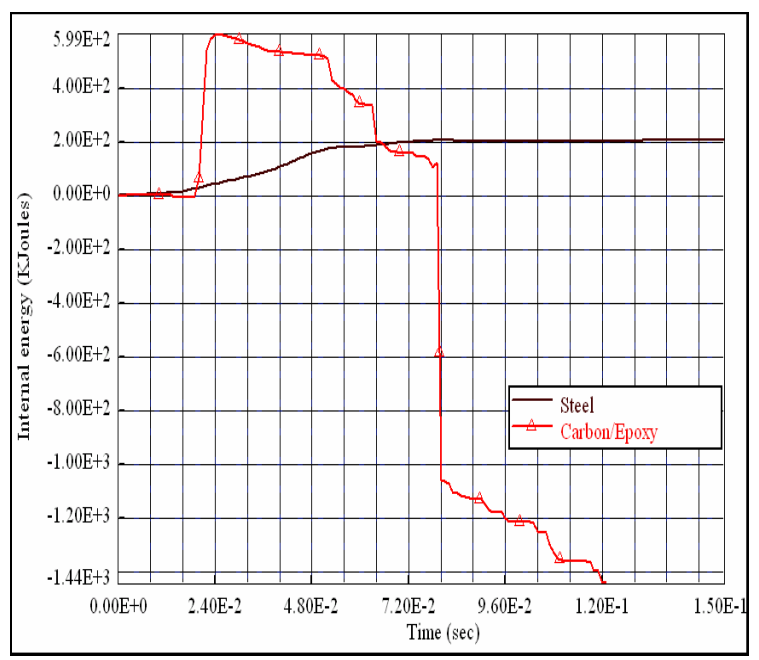

Fig. 15. Internal Energy due to total rails material change. 


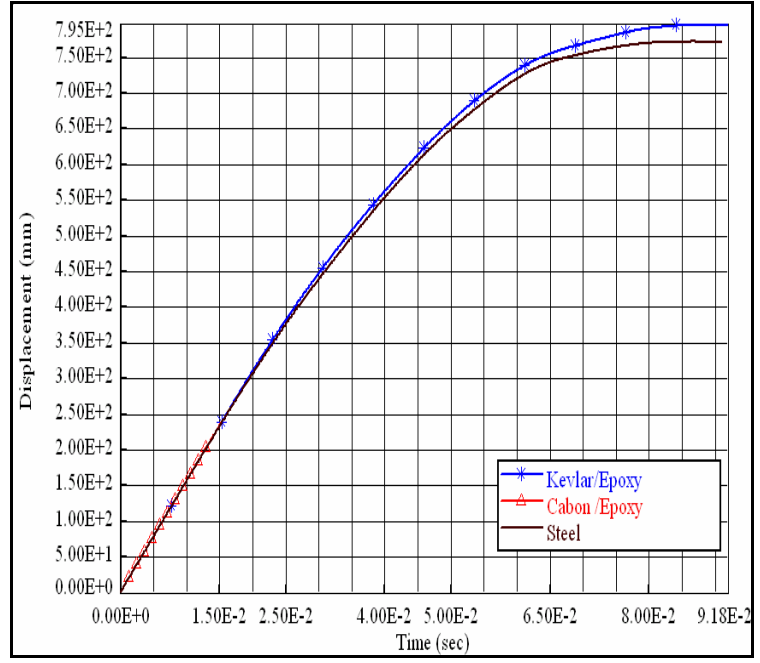

(a) Displacement

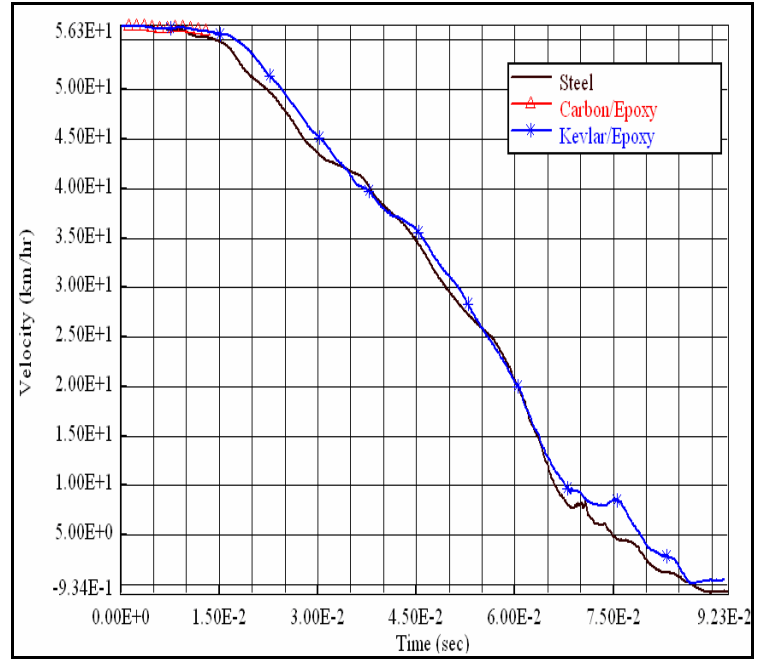

(b) Velocity

Fig. 16. Displacement and velocity of node 2061924 due to bumper material change.

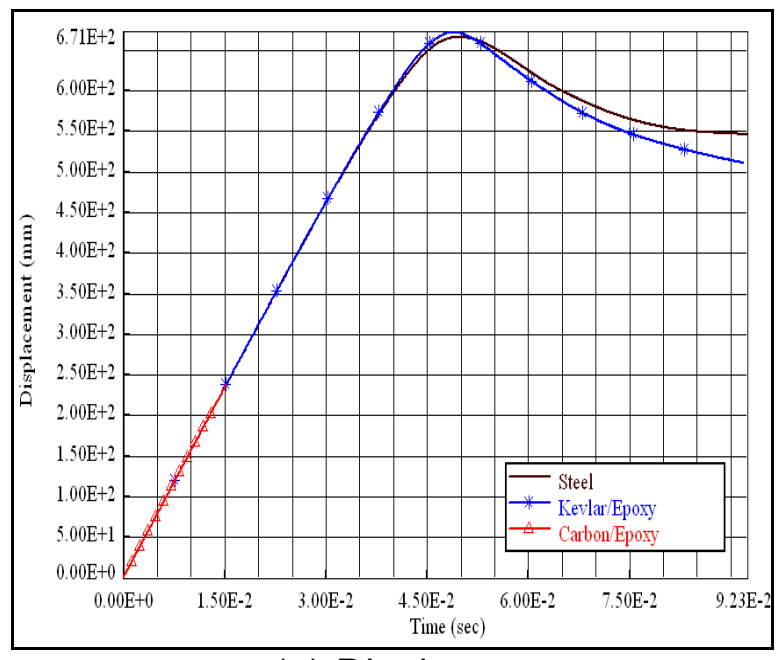

(a) Displacement

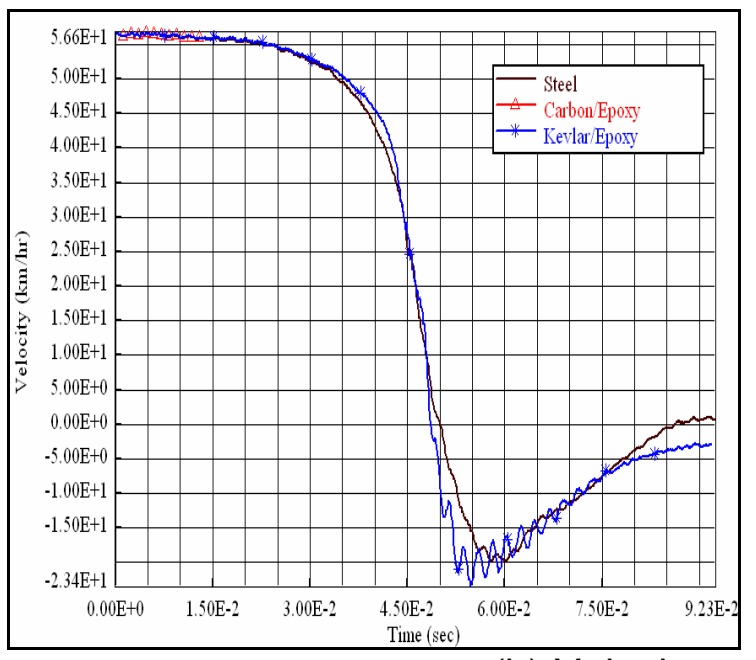

(b) Velocity

Fig. 17. Displacement and velocity of node 2061940 due to bumper material change.

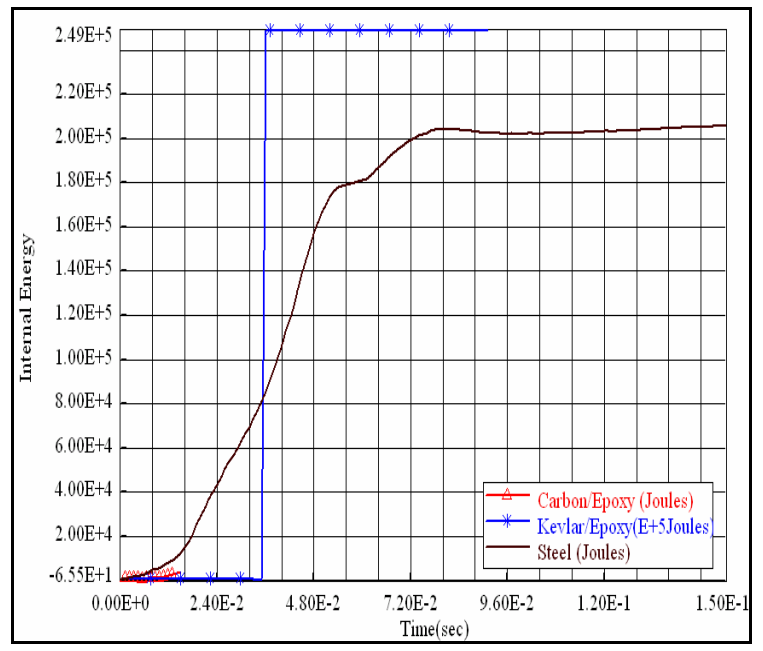

Fig. 18. Internal Energy due to bumper material change. 


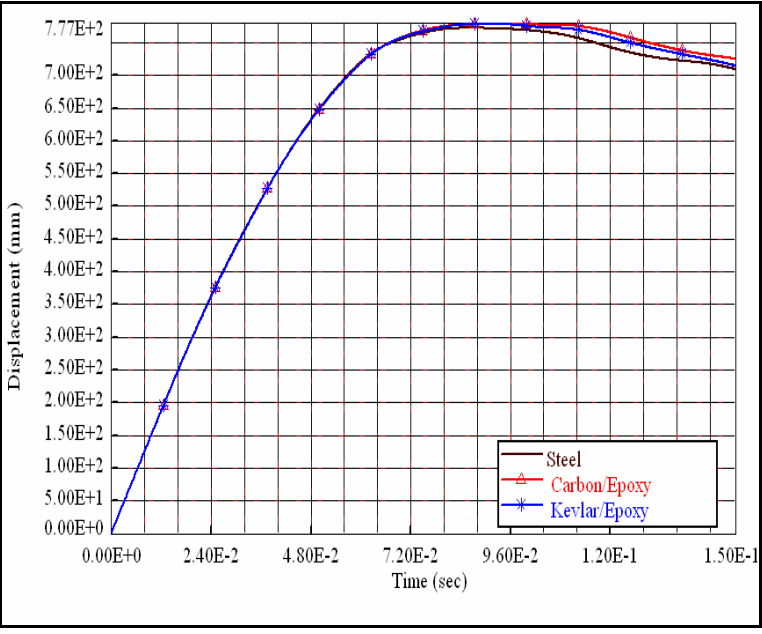

(a) Displacement

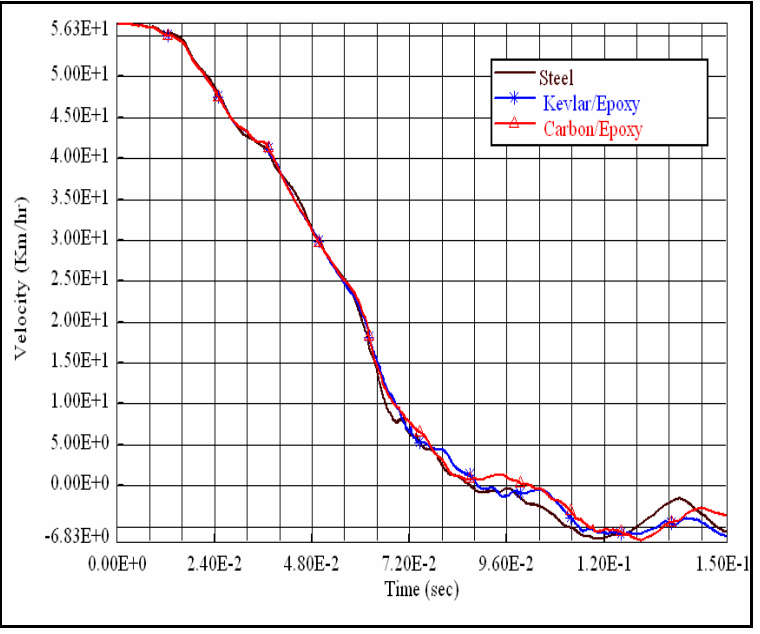

(b) Velocity

Fig. 19. Displacement and velocity of node 2061924 due to doors material change.

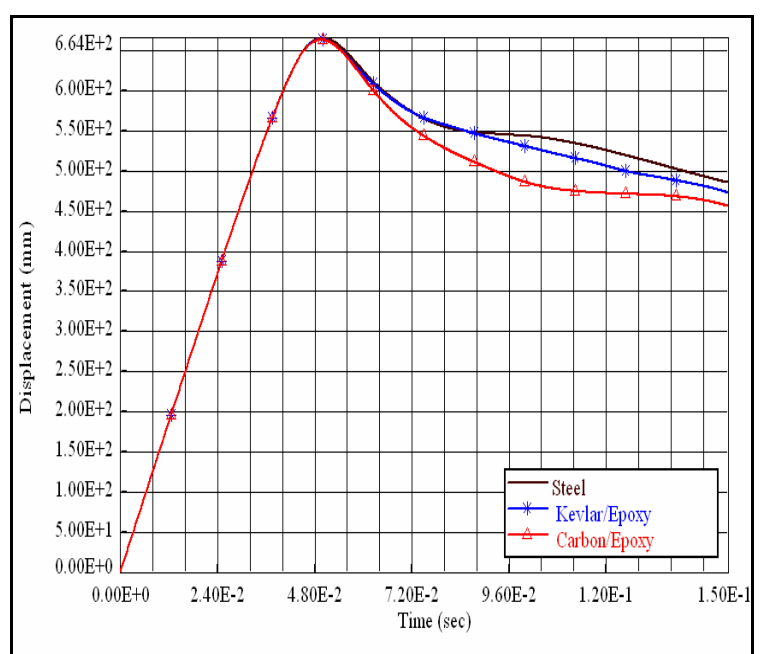

(a) Displacement

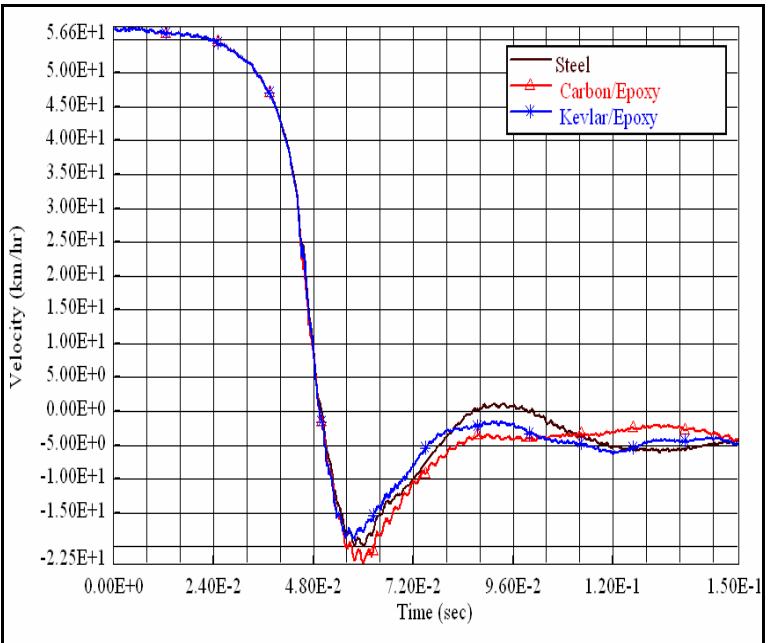

(b) Velocity

Fig. 20. Displacement and velocity of node 2061940 due to doors material change.

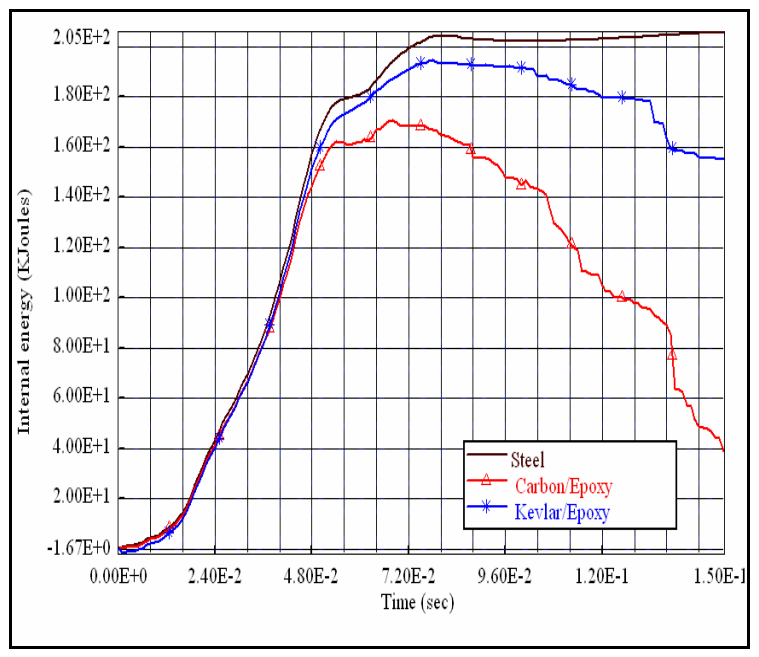

Fig. 21. Internal Energy due to doors material change 


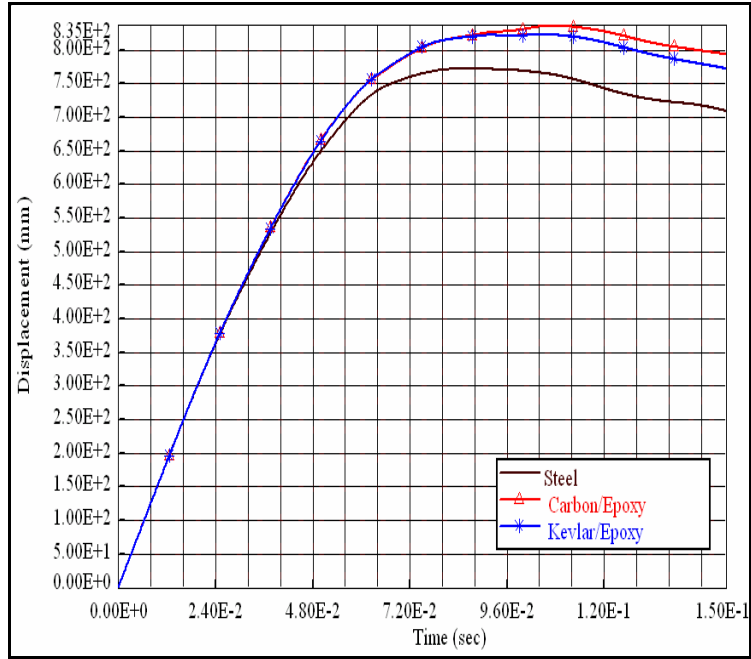

(a) Displacement

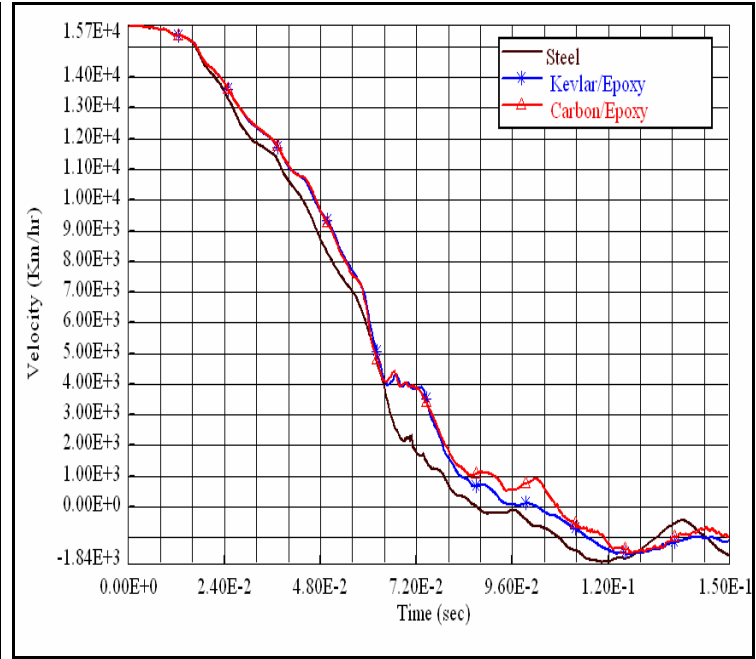

(b) Velocity

Fig. 22. Displacement and velocity of node 2061924 due to fender material change

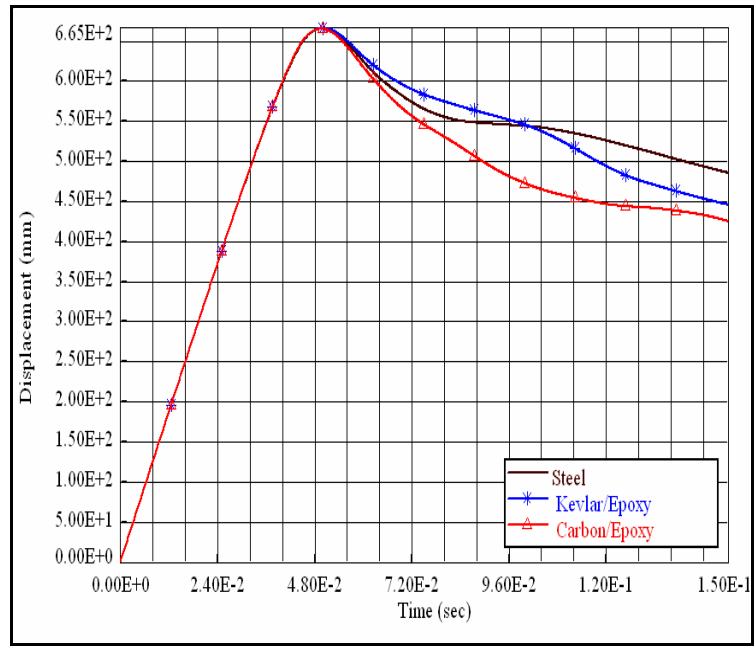

(a) Displacement

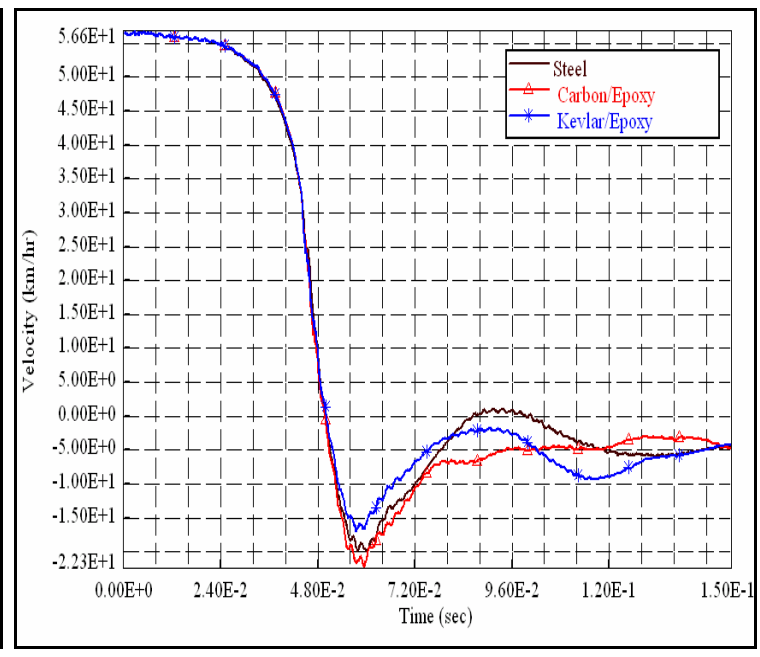

(b) Velocity

Fig. 23. Displacement and velocity of node 2061940 due to fender material change

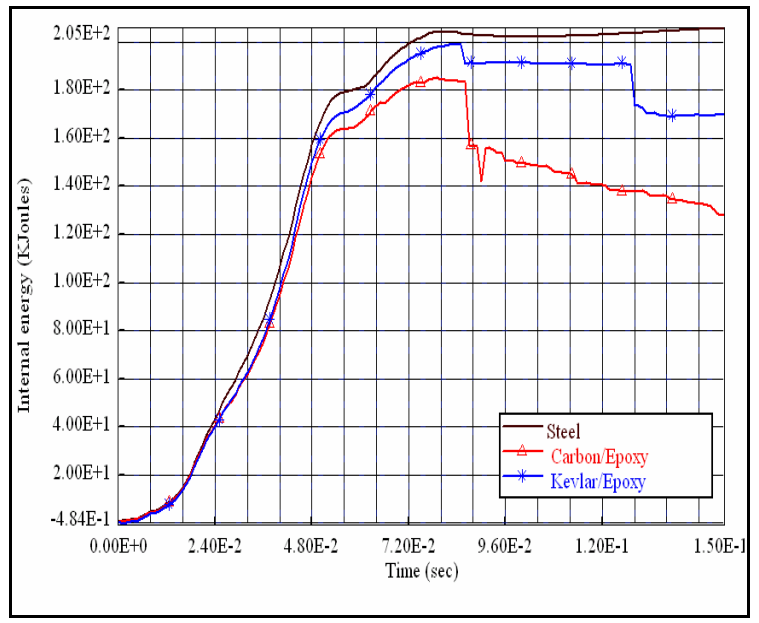

Fig. 24. Internal Energy due to fender material change. 


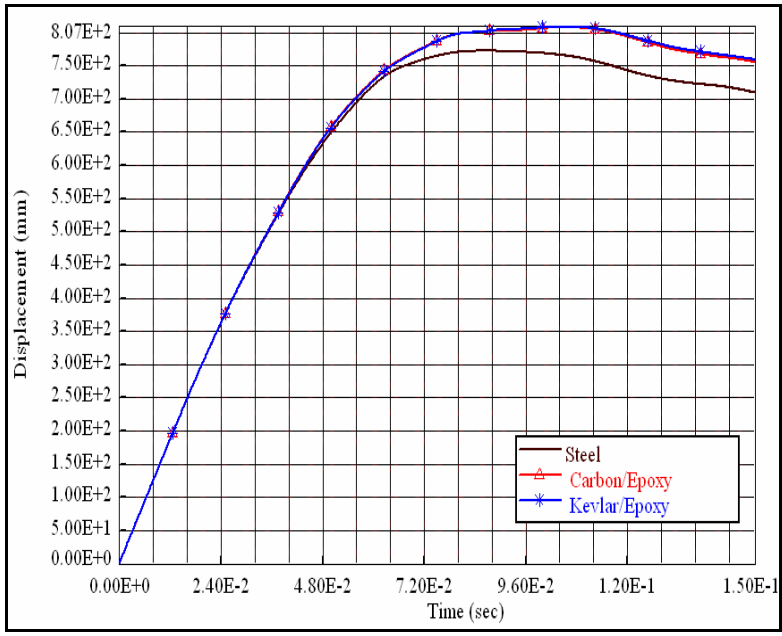

(a) Displacement

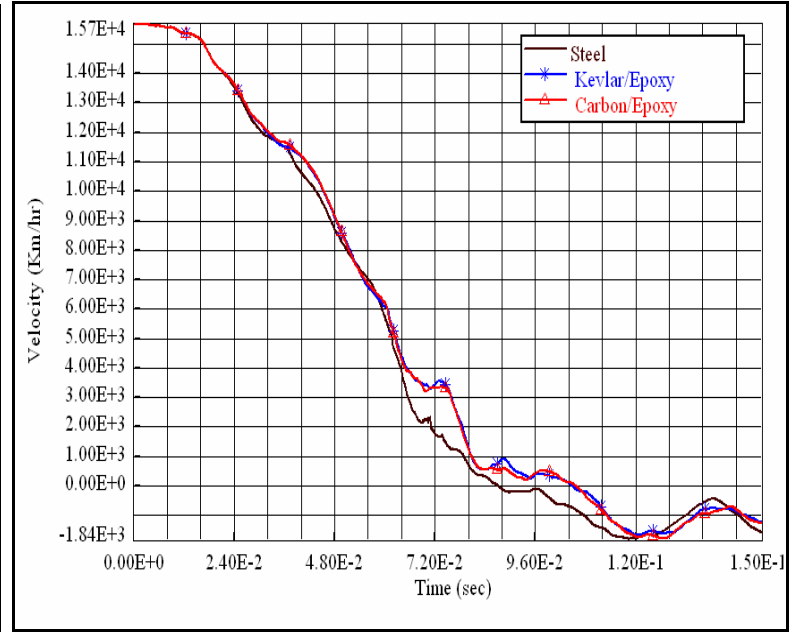

(b) Velocity

Fig. 25. Displacement and velocity of node 2061924 due to wheelhouse material change.

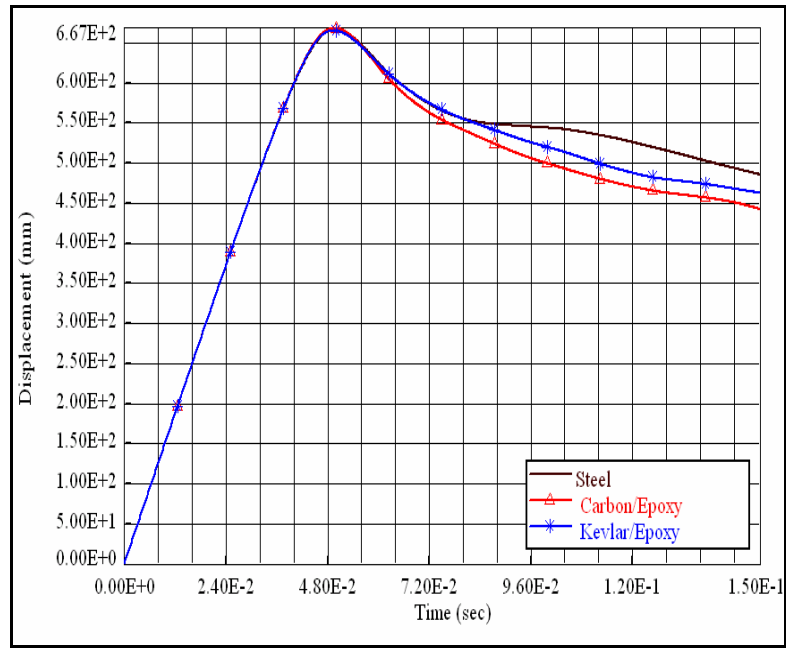

(a) Displacement

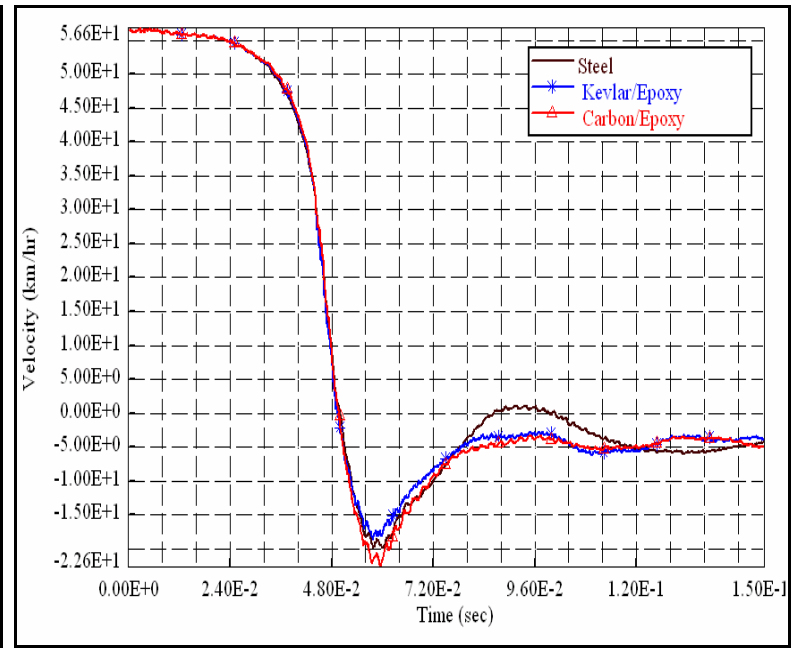

(b) Velocity

Fig. 26. Displacement and velocity of node 2061940 due to wheelhouse material change.

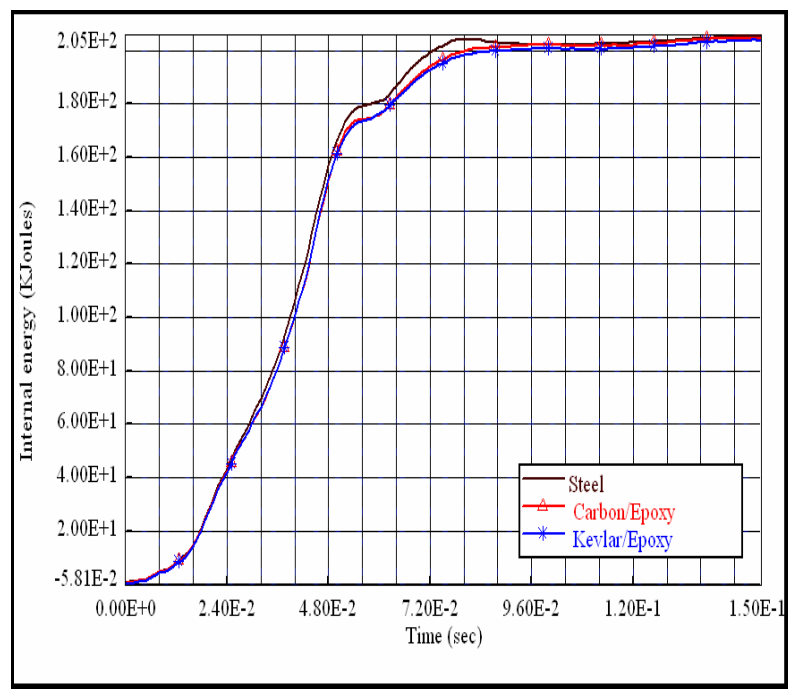

Fig. 27. Internal Energy due to wheelhouse material change. 


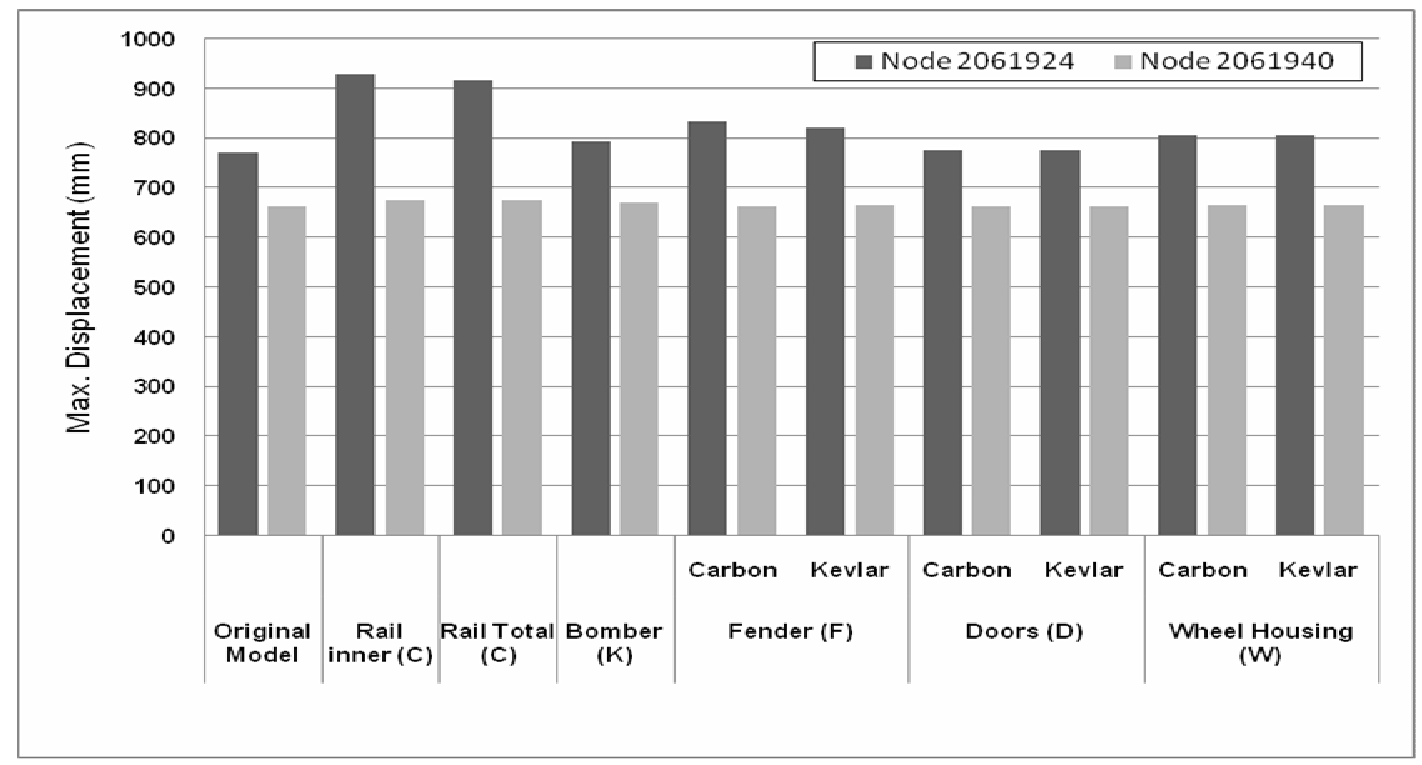

Fig. 28. Maximum displacement of every trial compared with the original model.

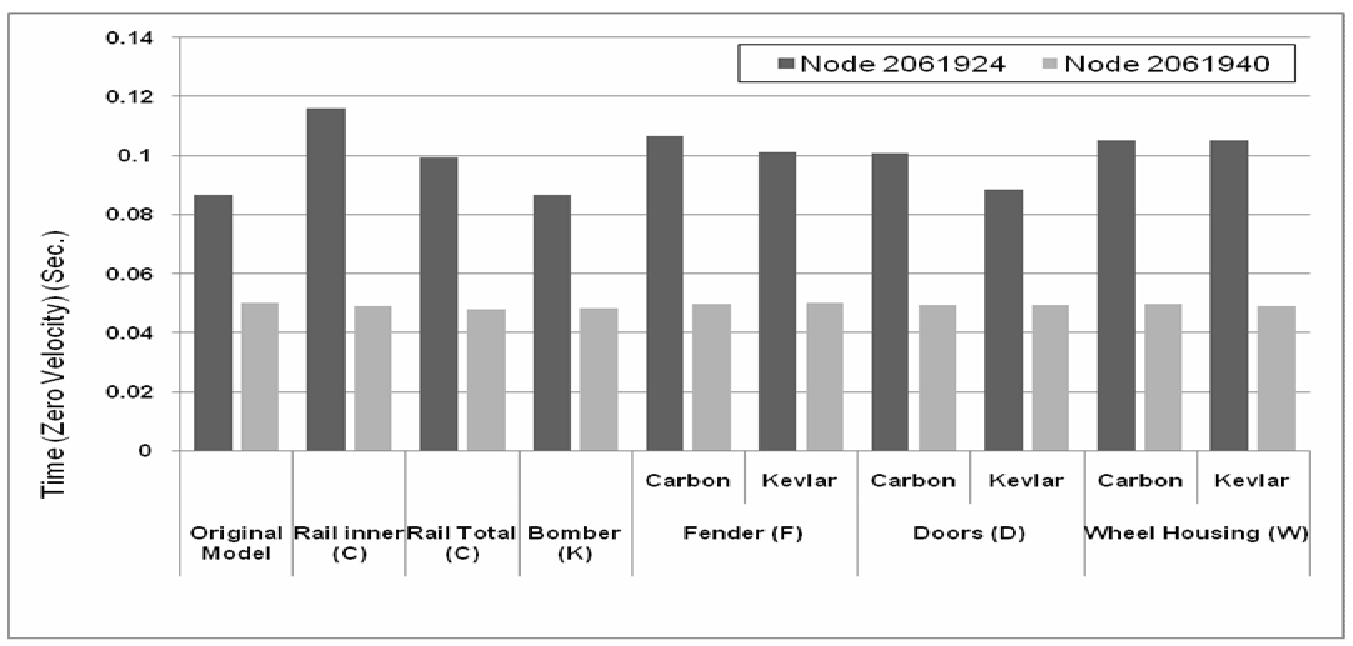

Fig. 29. Time (zero velocity) of every trial compared with the original model.

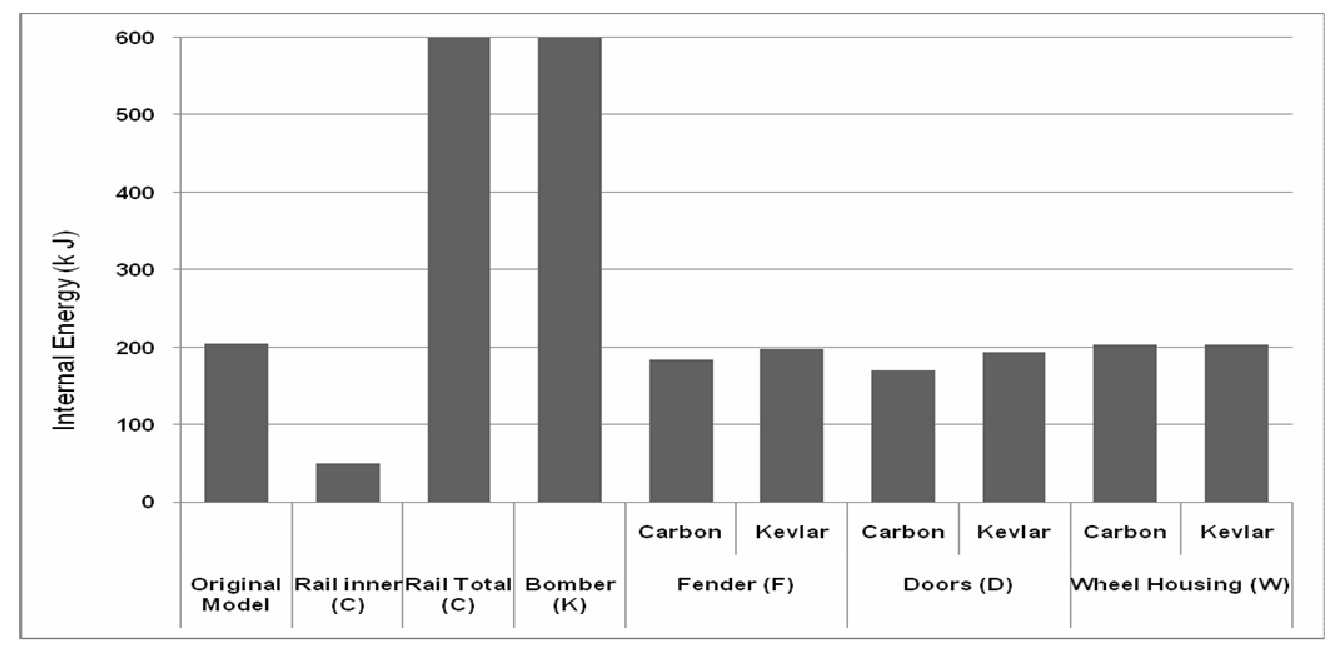

Fig. 30. Internal energy of every trial compared with the original model 

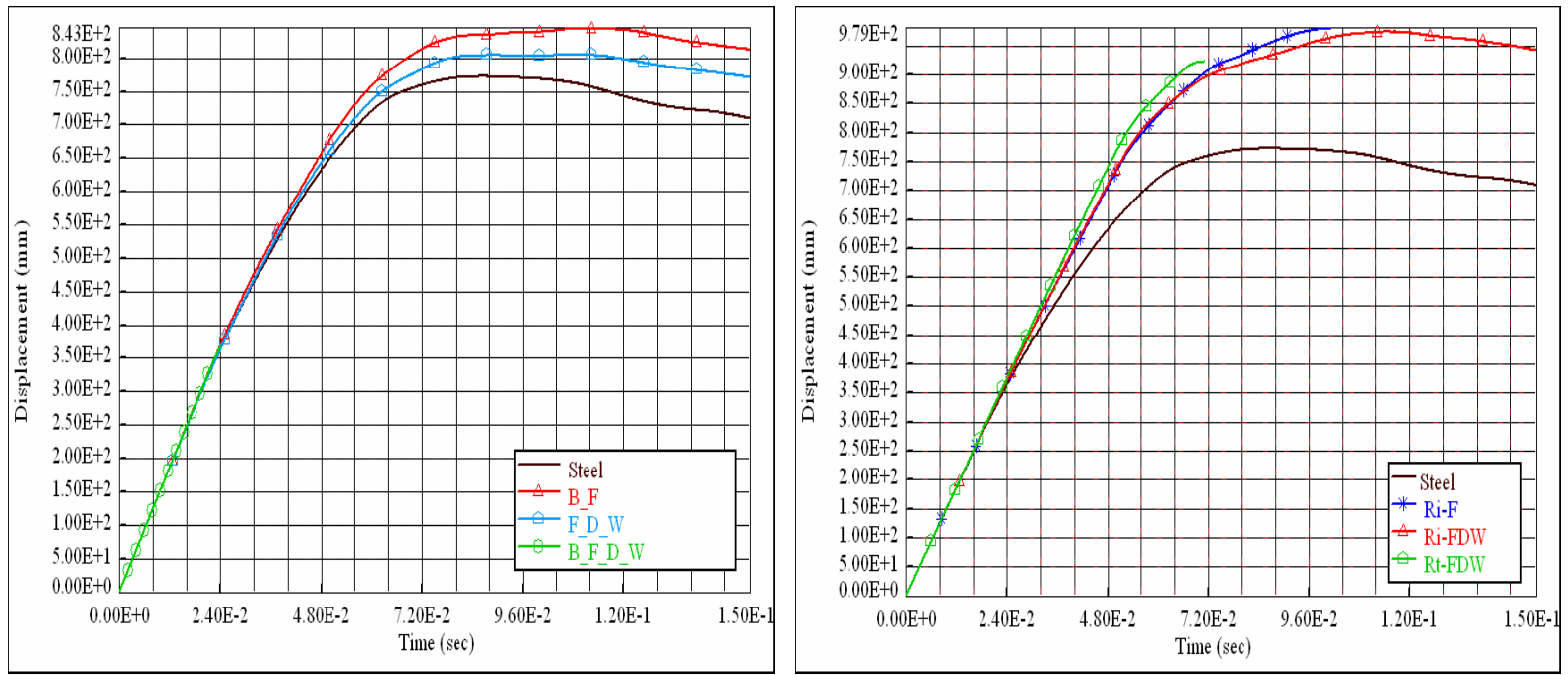

(a) Displacement
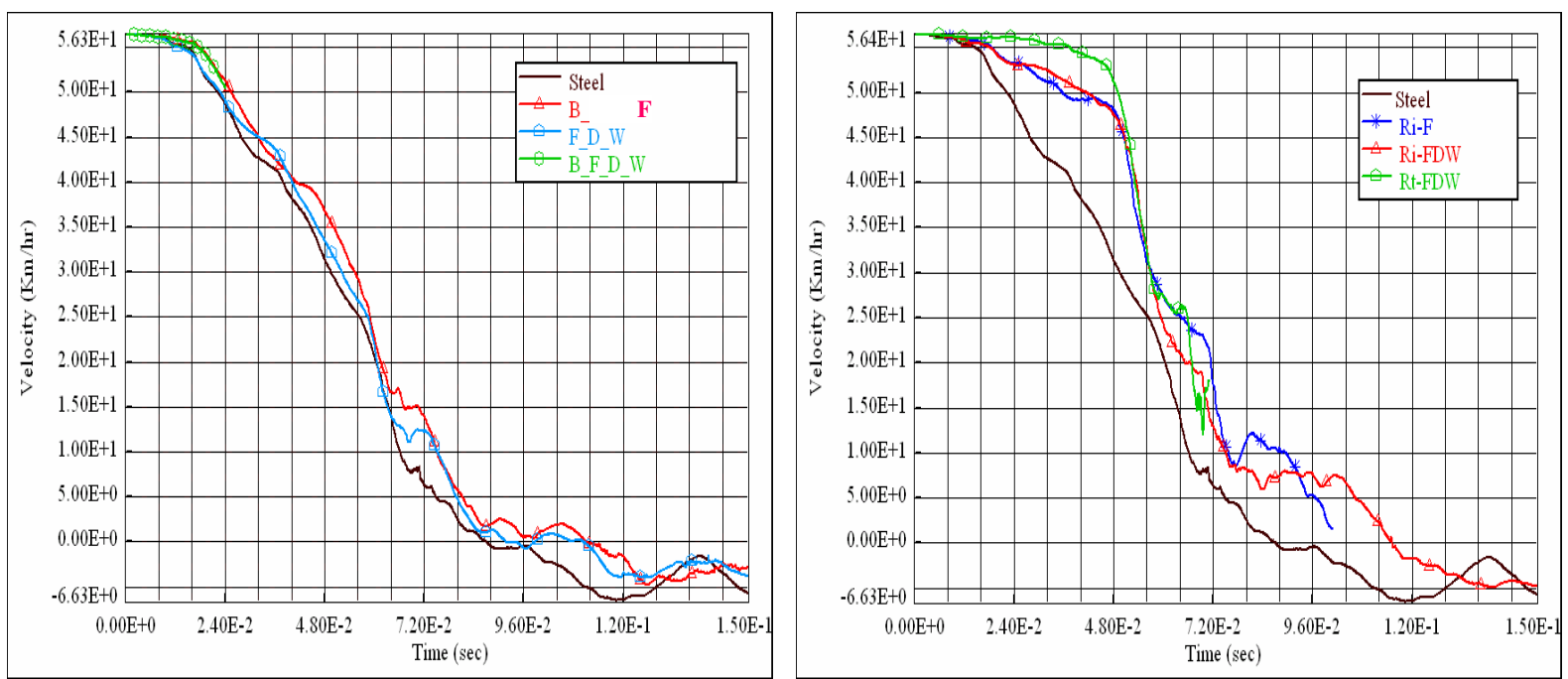

(b) Velocity

Fig. 31. Displacement and velocity of node 2061924 due to combinations of parts materials changing together. 

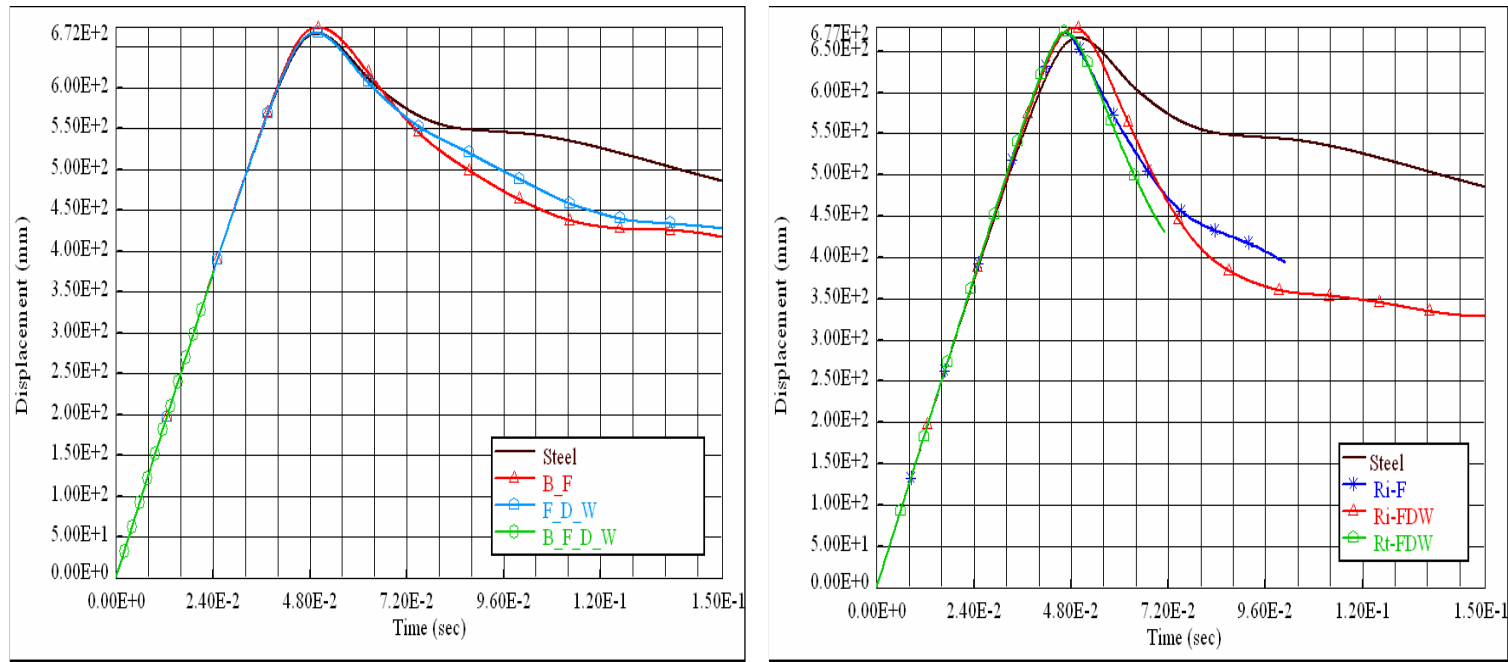

(a) Displacement
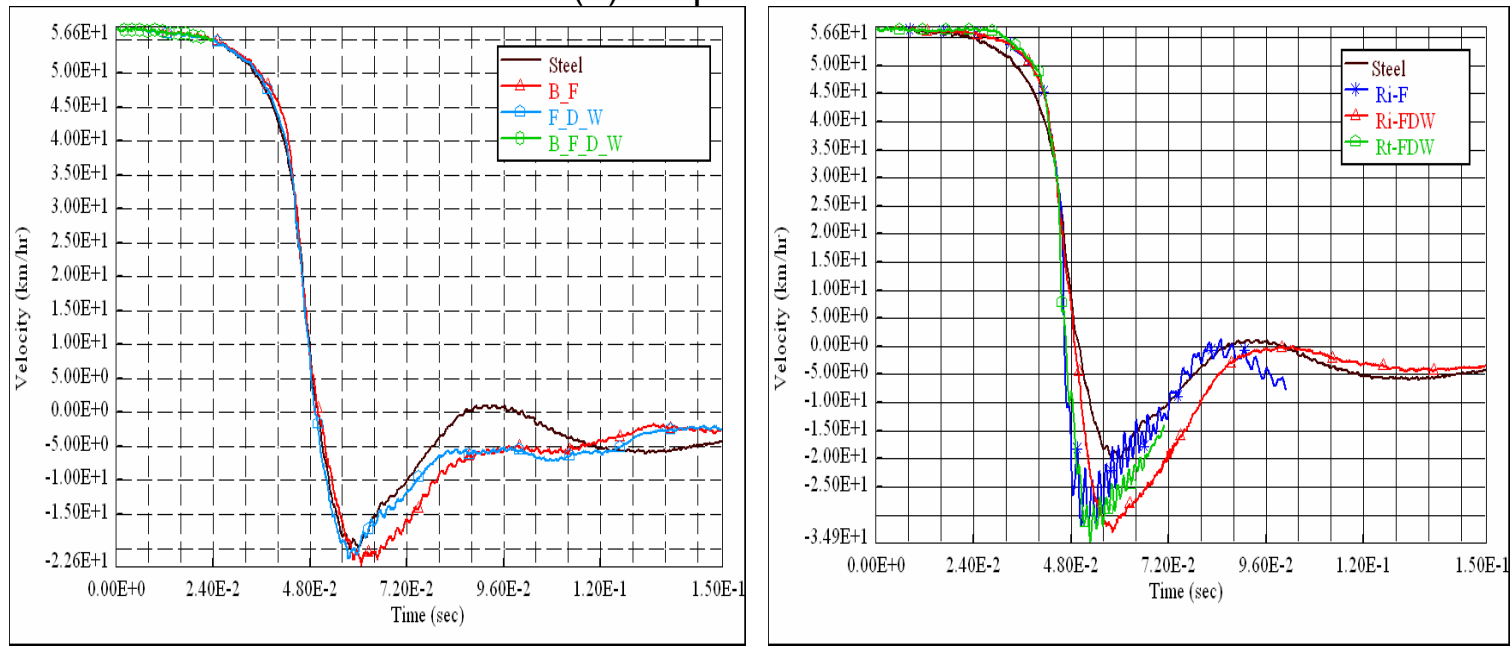

(b) Velocity

Fig. 32. Displacement and velocity of node 2061940 due to combinations of parts materials changing together
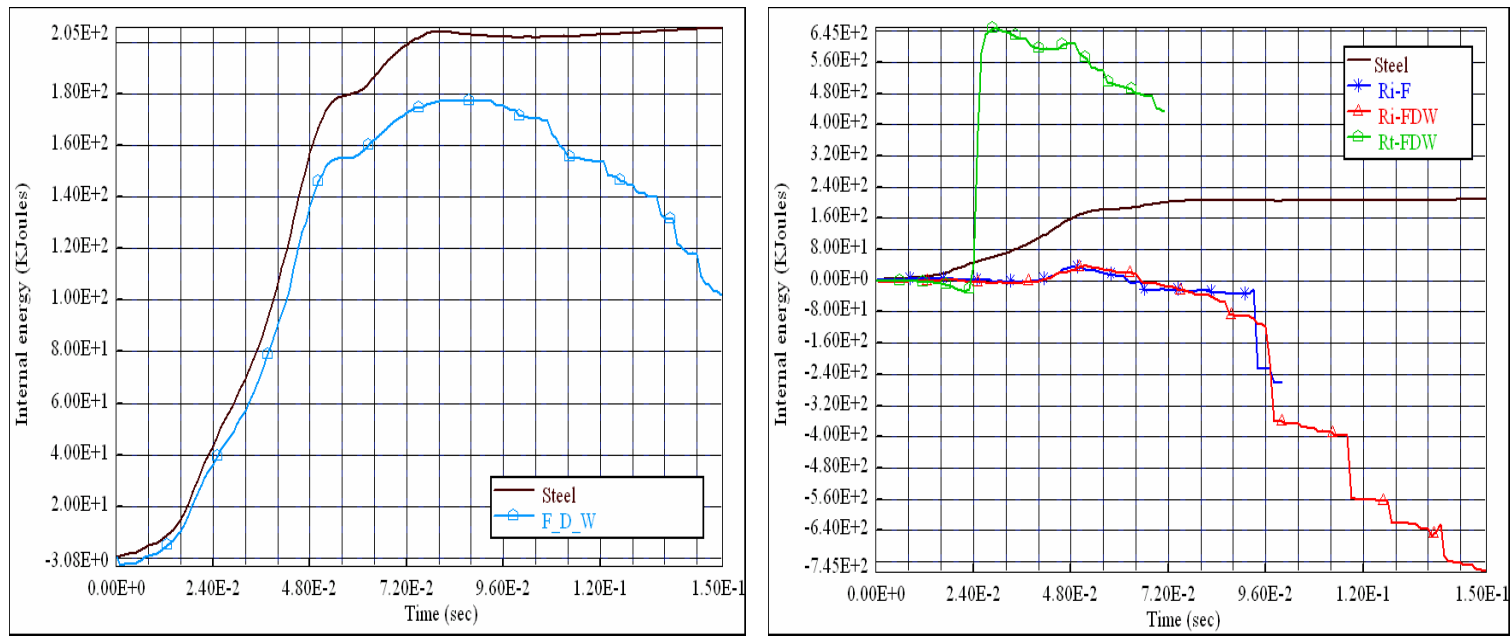

Fig. 33 Internal Energy due to combinations of parts materials changing together. 


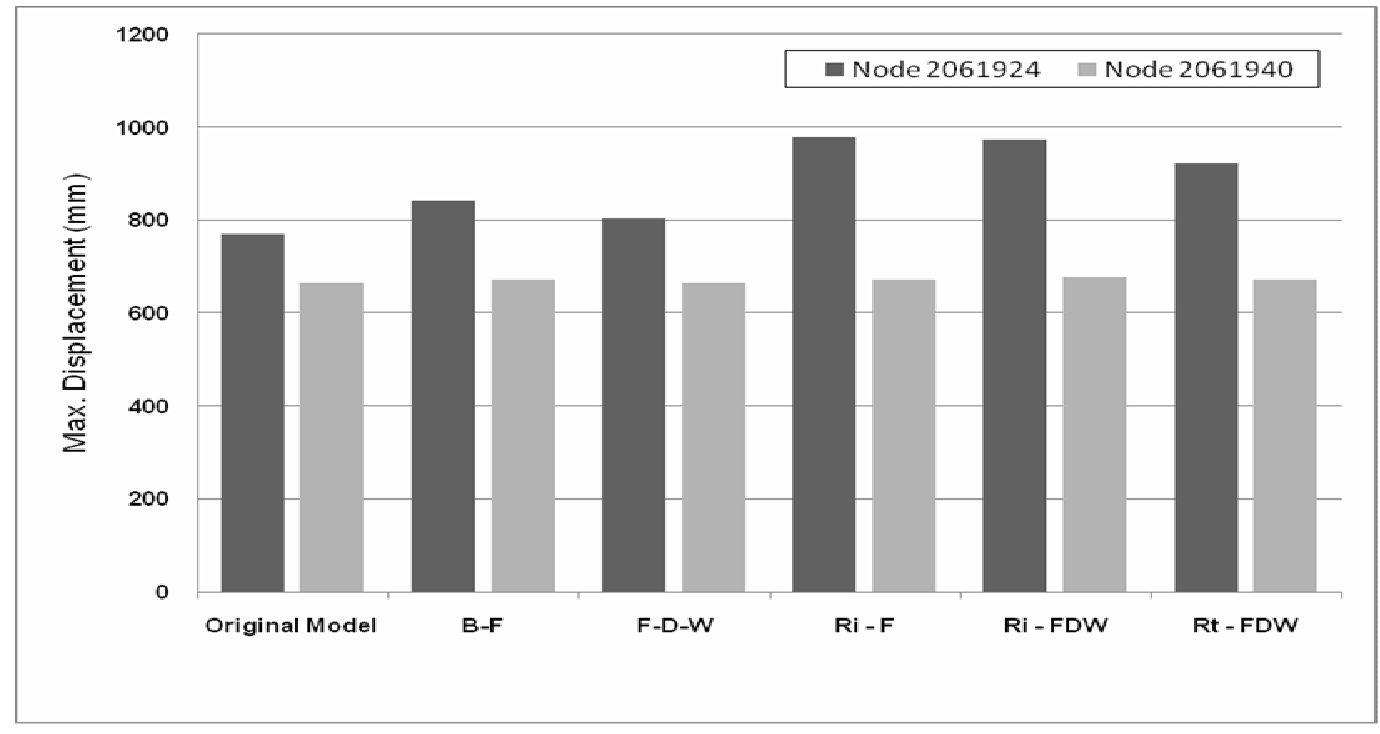

Fig. 34. Maximum displacement of combinations of parts materials changing together.

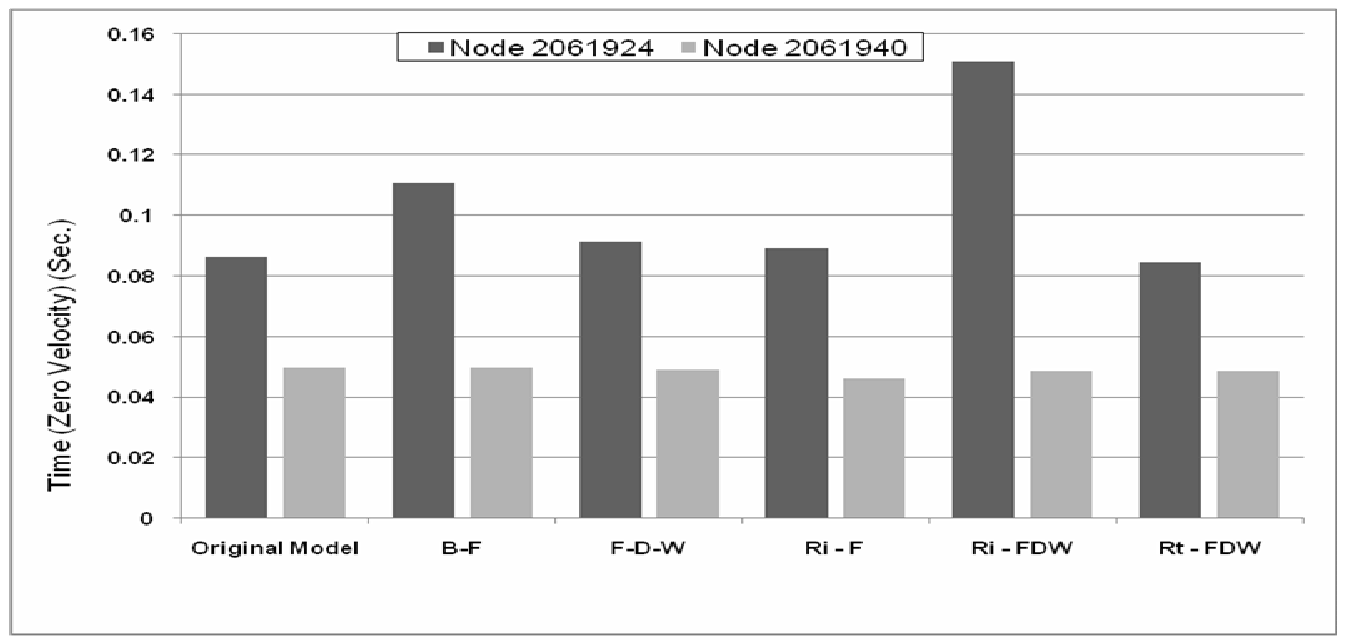

Fig. 35. Time (zero velocity) of combinations of parts materials changing together

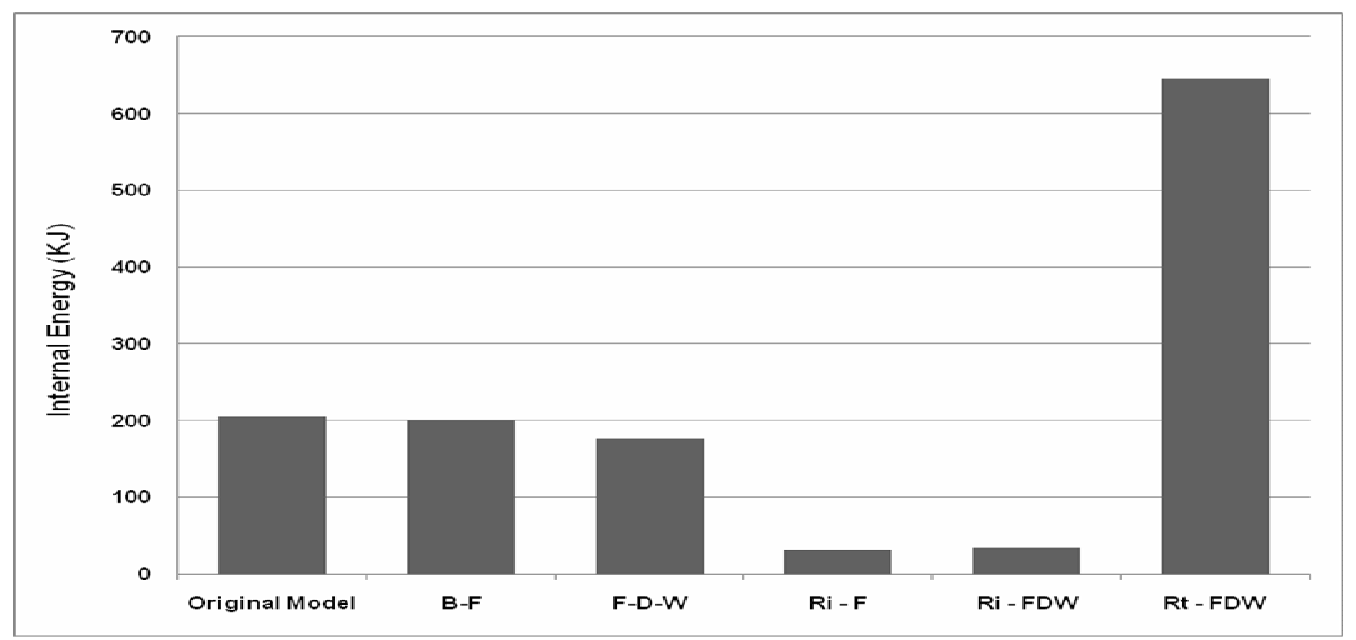

Fig. 36. Internal energy of combinations of parts materials changing together 